\title{
LINHA BÁSICA DE SUSCETIBILIDADE DE Spodoptera frugiperda (Lepidoptera: Noctuidae) A LUFENURON NA CULTURA DO MILHO
}

\section{FÁbio BorToletTo SCHMIDT}

\author{
Dissertação apresentada à Escola Superior de \\ Agricultura "Luiz de Queiroz", Universidade \\ de São Paulo, para obtenção do título de \\ Mestre em Ciências, Área de Concentração: \\ Entomologia.
}

PIRACICABA

Estado de São Paulo - Brasil

Maio - 2002 


\title{
LINHA BÁSICA DE SUSCETIBILIDADE DE Spodoptera frugiperda (Lepidoptera: Noctuidae) A LUFENURON NA CULTURA DO MILHO
}

\section{FÁbio BorToletto SCHMIDT}

Engenheiro Agrônomo

Orientador: Prof. Dr. CELSO OMOTO

\begin{abstract}
Dissertação apresentada à Escola Superior de Agricultura "Luiz de Queiroz", Universidade de São Paulo, para obtenção do título de Mestre em Ciências, Área de Concentração: Entomologia.
\end{abstract}

\author{
PIRACICABA \\ Estado de São Paulo - Brasil \\ Maio - 2002
}




\section{Dados Internacionais de Catalogação na Publicação (CIP) DIVISÃO DE BIBLIOTECA E DOCUMENTAÇ̃̃O - ESALQ/USP}

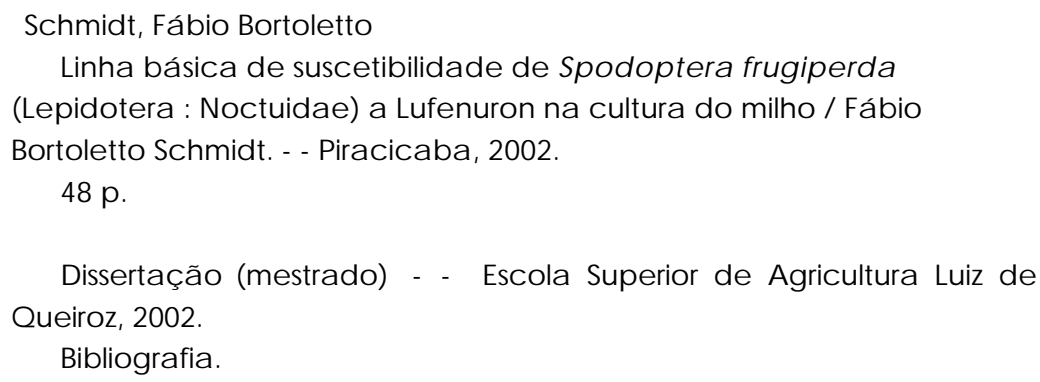

1. Insetic idas 2. Lagarta-do-cartuc ho 3. Milho 4. Resistência ao insetic ida I. Título

CDD 633.15

\section{"Permitida a cópia total ou parcial deste documento, desde que citada a fonte - $O$ autor"}




\section{Aos meus pais \\ José Francisco Schmidt e \\ Rosimeire A. B. Schmidt \\ OFEREÇO}

$* * * * * * * * * * * * *$

À minha esposa

Sandra C. Takaki Schmidt

DEDICO 


\section{AGRADECIMENTOS}

Ao professor Dr. Celso Omoto pela amizade, oportunidade e pelos ensinamentos transmitidos durante todo o período.

Aos professores do Departamento de Entomologia, Fitopatologia e Zoologia Agrícola pela experiência e conhecimentos transmitidos.

Ao IRAC-BR e em especial a Syngenta S.A. pelo apoio e fornecimento do produto para realização da pesquisa.

Aos alunos do Programa de Pós-graduação da Entomologia pela amizade e pelo companheirismo.

Ao colega Ruben Brito Silva pela s colaborações e amizade durante a execução do trabalho.

Ao meu irmão Juliano B. Schmidt pela amizade e auxílio na parte laboratorial.

Aos estagiários: Tiago, Riskdo, César, Thaís e Letícia pela colaboração na execução do projeto.

Ao colega Paulo César Bogorni pelo companheirismo.

À CAPES pela concessão da bolsa de estudos para a execução do trabalho.

Ao pessoal do Laboratório de Resistência de Artrópodes a Pesticidas pelo companheirismo e pelo bom convívio.

Ao Sr. Francisco Castillo pela amizade e auxílio na parte laboratorial.

Às bibliotecárias da Biblioteca da ESALQ/USP pelas correções das referências bibliográficas.

Aos meus pais pelo apoio em todos os momentos.

A minha esposa Sandra pela compreensão e carinho.

A todos aqueles que colaboraram para a execução deste trabalho.

A Deus. 


\section{SUMÁRIO}

Página

LISTA DE FIGURAS........................................................................... vii

LISTA DE TABELAS .......................................................................... ix

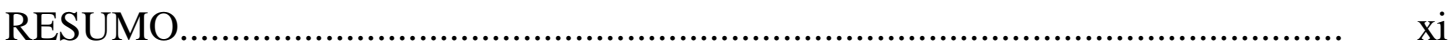

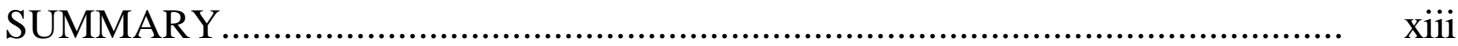

$1 \quad$ INTRODUÇÃO

2 REVISÃO DE LITERATURA...................................................... 3

2.1 Aspectos bioecológicos de Spodoptera frugiperda................................ 3

2.2 Resistência de Spodoptera frugiperda a inseticidas.............................. 5

2.3 Resistência de pragas a inibidores da biossíntese de quitina................... 5

2.3.1 Monitoramento da resistência............................................................. 7

2.3.2 Casos detectados de resistência.............................................................. 9

3 MATERIAL E MÉTODOS........................................................... 13

3.1 Coleta e criação de Spodoptera frugiperda.......................................... 13

3.2 Procedimentos de bioensaio ........................................................... 15

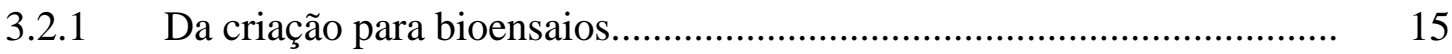

3.2.2 Da preparação do bioensaio .............................................................. 15

3.3 Caracterização de suscetibilidade de Spodoptera frugiperda ao

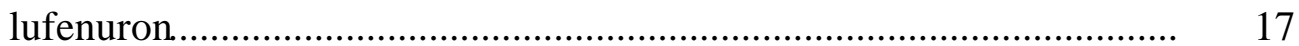

3.4 Monitoramento da suscetibilidade de populações de Spodoptera frugiperda ao lufenuron............................................................... 18

$4 \quad$ RESULTADOS E DISCUSSÃO.................................................. 19

4.1 Procedimentos de bioensaio........................................................... 19

4.2 Caracterização da linha básica de suscetibilidade de Spodoptera frugiperda ao lufenuron................................................................. 27

4.3 Monitoramento da suscetibilidade de populações de Spodoptera frugiperda ao lufenuron.................................................................... 29 
REFERÊNCIAS BIBLIOGRÁFICAS............................................................. 40 


\section{LISTA DE FIGURAS}

Página

1 Tratamento superficial de dieta artificial para realização de bioensaio..

2 Curvas de concentração-resposta de lagartas de $2^{\circ}$ instar da população suscetível de referência de Spodoptera frugiperda a lufenuron nos diferentes tempos de avaliação com bioensaio de tratamento superficial de dieta artificial

3 Curvas de concentração-resposta de lagartas de $3^{\circ}$ instar da população suscetível de referência de Spodoptera frugiperda a lufenuron nos diferentes tempos de avaliação com bioensaio de tratamento superficial de dieta artificial...........................................................

4 Curvas de concentração-resposta de lagartas de $2^{\circ}$ e $3^{\circ}$ instares da população suscetível de referência de Spodoptera frugiperda a lufenuron 4 dias (96 h) após a infestação, com bioensaio de tratamento

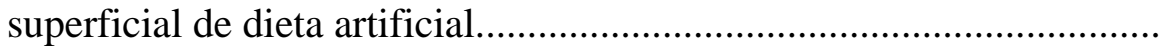

5 Curva de concentração-resposta de lagartas de $3^{\circ}$ instar da população RS-1 (suscetível de referência) de Spodoptera frugiperda a lufenuron 4 dias (96 h) após a infestação, com bioensaio de tratamento superficial de dieta artificial 
6 Monitoramento da suscetibilidade de lagartas de $3^{\circ}$ instar de Spodoptera frugiperda a lufenuron através do bioensaio de tratamento superficial de dieta artificial com concentração diagnóstica de 3,2 $\mu \mathrm{g}$ de lufenuron / mL de água .............................................................

7 Monitoramento da suscetibilidade de lagartas de $3^{\text {o }}$ instar de Spodoptera frugiperda a lufenuron através do bioensaio de tratamento superficial de dieta artificial com concentração diagnóstica de $10 \mu \mathrm{g}$ de lufenuron / mL de água (ingestão)

8 Curvas de concentração versus resposta de populações de Spodoptera frugiperda provenientes dos Estados do RS, PR, SP, MG e GO. Bioensaio de tratamento superficial de dieta artificial com lagartas de $3^{\circ}$ instar expostas por $96 \mathrm{~h}$ ao lufenuron. 


\section{LISTA DE TABELAS}

Página

1 Respostas de lagartas de $2^{\mathbf{o}}$ instar da população suscetível de referência de Spodoptera frugiperda a lufenuron em diferentes tempos de avaliação com bioensaio de tratamento superficial de dieta artificial.

2 Respostas de lagartas de $3^{\circ}$ instar da população suscetível de referência de Spodoptera frugiperda a lufenuron em diferentes tempos de avaliação com bioensaio de tratamento superficial de dieta artificial..

3 Respostas de lagartas de $2^{\circ}$ e $3^{\circ}$ instar da população suscetível de referência de Spodoptera frugiperda a lufenuron 96 horas após infestação com bioensaio de tratamento superficial de dieta artificial

4 Monitoramento da suscetibilidade de lagartas de $3^{\circ}$ instar de Spodoptera frugiperda a lufenuron através do bioensaio de tratamento superficial de dieta artificial com concentração diagnóstica de 3,2 $\mu \mathrm{g}$ de lufenuron / $\mathrm{mL}$ de água

5 Monitoramento da suscetibilidade de lagartas de $3^{\circ}$ instar de Spodoptera frugiperda a lufenuron através do bioensaio de tratamento superficial de dieta artificial com concentração diagnóstica de $10 \mu \mathrm{g}$ de lufenuron / $\mathrm{mL}$ de água 
6 Respostas de lagartas de $3^{\circ}$ instar de populações de Spodoptera frugiperda de 5 estados brasileiros ao lufenuron através do bioensaio de tratamento superficial de dieta artificial ....................................... 36 


\title{
LINHA BÁSICA DE SUSCETIBILIDADE DE Spodoptera frugiperda (Lepidoptera: Noctuidae) A LUFENURON NA CULTURA DO MILHO
}

\author{
Autor: FÁBIO BORTOLETTO SCHMIDT \\ Orientador: Prof. Dr. CELso OMOTO
}

\section{RESUMO}

Lufenuron é um novo inseticida do grupo dos inibidores da biossíntese de quitina utilizado para o controle de Spodoptera frugiperda J. E. Smith (Lepidoptera: Noctuidae) na cultura do milho. O uso deste inseticida para o controle de $S$. frugiperda tem aumentado muito nos últimos anos. Este incremento pode ser atribuído à sua alta eficiência e devido ao desenvolvimento da resistência desta praga aos produtos tradicionalmente recomendados para o seu controle (por exemplo, fosforados e piretróides). Neste trabalho, a linha básica de suscetibilidade de $S$. frugiperda foi obtida com o intuito de implementar um programa proativo de manejo da resistência. Para a caracterização da suscetibilidade de populações de S. frugiperda ao lufenuron, utilizour se o bioensaio que consistiu no tratamento superficial de dieta artificial. Lagartas de $2^{\circ}$ e $3^{\circ}$ instar foram expostas à dieta tratada por um período de até 5 dias $(120 \mathrm{~h})$. A partir deste estudo concluiu-se que a utilização de lagartas de $3^{\circ}$ instar expostas por um 
período de 4 dias (96 h) foi o procedimento de bioensaio mais adequado. Baseado na curva de concentração-resposta da população suscetível de referência, as concentrações de 3,2 e 10,0 $\mu \mathrm{g}$ de lufenuron / $\mathrm{mL}$ de água destilada foram escolhidas para o monitoramento da suscetibilidade. Resultados do monitoramento da suscetibilidade de populações de $S$. frugiperda provenientes dos principais Estados produtores de milho do Brasil (Rio Grande do Sul, Paraná, São Paulo, Goiás e Minas Gerais) mostraram diferenças significativas quanto à suscetibilidade ao lufenuron. Esses resultados sugerem a necessidade da implementação de estratégias de manejo da resistência para preservar a vida útil do lufenuron no controle de S. frugiperda no Brasil. 


\title{
BASELINE SUSCEPTIBILITY OF Spodoptera frugiperda (Lepidoptera: Noctuidae) TO LUFENURON IN CORN
}

\author{
Author: FÁBIO BORTOLETTO SCHMIDT \\ Adviser: Prof. Dr. CELSO OMOTO
}

\section{SUMMARY}

Lufenuron is a newly benzoylphenyl urea chitin synthesis inhibitor insecticide. The use of this compound to control Spodoptera frugiperda J. E. Smith (Lepidoptera: Noctuidae) has increased significantly in the past years. This increase can be attributed to its high activity against $S$. frugiperda and to the reduction of efficacy due to resistance to some traditional insecticides (such as phosphates, carbamates and pyrethroids) recommended for controlling this pest. In this study, a baseline susceptibility data of $S$. frugiperda populations to lufenuron were obtained for implementing a proactive resistance management program. An artificial diet treatment surface bioassay was used to characterize the response to lufenuron in a susceptible strain. Second and third instar larvae were exposed to the treated diet up to 5 days $(120 \mathrm{~h})$. A period of 4 days $(96 \mathrm{~h})$ and third instar larvae were defined as standard procedures for bioassays. After the characterization of the susceptible population, diagnostic concentrations of 3.2 and 10.0 
$\mu \mathrm{g}$ of lufenuron / $\mathrm{mL}$ of distilled water were chosen for monitoring the susceptibility. A survey of susceptibility to lufenuron was conducted in field populations of S. frugiperda collected from major corn-growing regions located in the States of Rio Grande do Sul, Paraná, São Paulo, Goiás and Minas Gerais. Significant differences in susceptibility to lufenuron were detected among S. frugiperda populations. These results suggest the need to implement resistance management strategies to preserve the lifetime of lufenuron for controlling S. frugiperda in Brazil. 


\section{INTRODUÇÃO}

O Brasil produziu 34,5 milhões de toneladas de milho na safra 2000/2001, o que garante a $3^{\text {a }}$ posição entre os países produtores de milho no murolo (FNP, 2002). Os maiores estados produtores de milho no Brasil foram Paraná, Minas Gerais, Rio Grande do Sul, São Paulo, Goiás e Santa Catarina (FNP, 2002).

A produção de milho no Brasil tem sofrido grandes avanços nos últimos anos, devido principalmente às novas tecnologias disponíveis para os agricultores e à expansão da época de produção em áreas tradicionais (Garcia, 1994). Por exemplo, o cultivo de milho em alguns estados como Minas Gerais, Goiás e São Paulo, tem sido possível durante todo ano em propriedades com sistema de irrigação, sendo os plantios realizados na safra, na safrinha e no inverno (Esteves et al., 1994).

Com a expansão da época de cultivo do milho, os problemas fitossanitários têm se agravado nos últimos anos. Dentre as pragas, a lagarta-do-cartucho, Spodoptera frugiperda J. E. Smith, é uma das principais na cultura (Viana, 1994). Os seus danos podem chegar a $34 \%$ de quebra de produção, comprometendo severamente a rentabilidade da cultura (Carvalho, 1970). A lagarta-do-cartucho do milho é uma espécie polífaga que ataca várias culturas de importância econômica em diversos países. No Brasil, além do milho, pode danificar importantes culturas, tais como arroz, algodão, sorgo, soja, feijão e amendoim.

O controle de $S$. frugiperda tem sido realizado principalmente pelo uso de produtos químicos. Sabe-se que o uso indiscriminado de um produto químico pode levar à evolução da resistência a níveis bastante críticos. Fracassos no controle desta praga são freqüentemente relatados com o uso de produtos tradicionais como fosforados e piretróides no Brasil. Há na literatura inúmeros casos documentados de resistência de 
S. frugiperda a inseticidas. Yu (1991) verificou que na Flórida a razão de resistência a piretróides variou de 2 a 216 vezes. Para os fosforados, a intensidade variou de 12 a 271 vezes e para os carbamatos de 14 a 192 vezes.

O lufenuron é um novo inseticida do grupo dos reguladores do crescimento dos insetos que vem sendo amplamente utilizado no controle de S. frugiperda no Brasil. Atualmente, o lufenuron é responsável por cerca de $40 \%$ da área tratada com inseticidas para o controle de $S$. frugiperda em milho. Este produto tem como principais características a sua alta eficiência no controle da lagarta, a baixa toxicidade para mamíferos e a alta seletividade a inimigos naturais, adequando-se ao contexto do Manejo Integrado de Pragas (MIP). Por apresentar tais características e também pela ineficácia de piretróides e fosforados em algumas regiões, a aceitação dos agricultores pelo produto foi rápida fazendo-se necessário a implementação de uma estratégia preventiva de manejo da resistência de $S$. frugiperda ao lufenuron visando prolongar sua vida útil. Sendo assim, este trabalho teve como objetivo coletar subsídios para a implementação de um programa de manejo preventivo da resistência de S. frugiperda ao lufenuron no Brasil, com enfoque na padronização da metodologia de bioensaio para a detecção da resistência e avaliação da variabilidade na suscetibilidade ao lufenuron em populações de $S$. frugiperda coletadas nas principais regiões produtoras de milho do Brasil. 


\section{REVISÃO DE LITERATURA}

\subsection{Aspectos bioecológicos de Spodoptera frugiperda}

Segundo Georghiou \& Taylor (1977 a,b) os fatores que afetam a evolução da resistência são divididos em genéticos, bioecológicos e operacionais. O estudo destes fatores pode mostrar a maneira mais adequada de se interferir no sistema para evitar ou retardar a evolução da resistência.

Dentre os fatores bioecológicos de Spodoptera frugiperda J. E. Smith, o ciclo de vida, a fecundidade, a capacidade de migração e o hábito alimentar são características relevantes e que precisam ser considerados num programa de manejo da resistência.

Estrada (1960), criando S. frugiperda em dieta natural, observou que inseto completou o ciclo de vida em aproximadamente 30 dias, podendo assim ocorrer até 12 gerações em um ano no Brasil. Em estudos de biologia de $S$. frugiperda em dieta artificial à base de feijão, germe de trigo e levedura de cerveja realizados por Nalim (1991) foi obtida duração da fase larval de 17 dias em condições controladas de temperatura de $25 \pm 2^{\circ} \mathrm{C}$, UR $50 \pm 10 \%$ e fotofase de $14 \mathrm{~h}$. O período de pupa foi de 13 dias. A longevidade dos adultos foi de 16 dias com período de pré-oviposição e de oviposição de 5 e 9 dias, respectivamente. A duração do período ovo-adulto foi de 33 dias, semelhante ao período obtido por Estrada (1960). O elevado número de gerações de $S$. frugiperda durante um ano significa que a praga pode estar sujeita à uma alta pressão seletiva com inseticidas, aumentando a possibilidade do desenvolvimento da resistência. 
As mariposas de $S$. frugiperda apresentam reprodução sexuada. Em dieta artificial, Nalim (1991) obteve média de 254 ovos por postura num total de 2174 ovos por fêmea, o que evidencia a alta capacidade reprodutiva desta espécie.

S. frugiperda é uma espécie polífaga, com ocorrência em milho, sorgo, trigo, aveia, arroz, pastagem, linho, algodão, amendoim beringela, batata além de plantas ornamentais e silvestres (Rizzo \& La Rossa, 1992). Segundo Georghiou \& Taylor (1986), o polifagismo pode influenciar o desenvolvimento da resistência de duas formas: retardando devido à imigração de indivíduos suscetíveis de áreas não tratadas (outras plantas) para a cultura, ou favorecendo devido à alta concentração enzimática típica destes insetos, a qual poderia favorecer a degradação de um produto químico.

Há na literatura estudos que mostram S. frugiperda atacando preferencialmente a cultura do arroz em detrimento ao milho. Em experimentos conduzidos por Pashley \& Martin (1987), fêmeas de S. frugiperda coletadas em milho não se acasalaram com machos coletados em arroz, ao passo que fêmeas coletadas em arroz se acasalaram com machos coletados em milho e produziram descendentes férteis. $\mathrm{O}$ retrocruzamento das fêmeas $F_{1}$ e também o cruzamento entre eles $\left(F_{1} \times F_{1}\right)$ foram observados e os resultados mostraram que existe uma barreira em algum estágio nas 2 direções dos cruzamentos entre as linhagens de $S$. frugiperda, suportando a hipótese que $S$. frugiperda é composta por raças associadas aos hospedeiros.

Posteriormente, Pashley et al. (1992) mostraram que as barreiras de isolamento entre linhagens de $S$. frugiperda são formadas por vários mecanismos. O mais importante deles é a diferença ms horários para acasalamento e postura. A linhagem proveniente do milho realiza a postura nos dois terços iniciais da noite enquanto a linhagem do arroz utiliza o terço final. De acordo com Veenstra et al. (1995) há fatores comportamentais e fisiológicos associados à utilização de um ou outro hospedeiro, permitindo a diferenciação de linhagens baseado nessas características.

A partir dos trabalhos envolvendo preferência diferenciada de S. frugiperda por hospedeiros específicos fica evidente que as áreas de refúgio para indivíduos suscetíveis em hospedeiros alternativos devem ser avaliadas com cautela em programas de manejo da resistência. 


\subsection{Resistência de Spodoptera frugiperda a inseticidas}

Apesar dos grandes avanços nos programas de MIP na cultura do milho (Cruz, 1995), o controle de S. frugiperda tem sido realizado principalmente através do uso de produtos químicos (Viana, 1994; Yu, 1983 e Yu \& Nguyen, 1994).

O grande desafio em programas de controle de pragas envolvendo o uso de compostos químicos é evitar a seleção de linhagens resistentes (Metcalf, 1980). Dentre as consequiências do desenvolvimento da resistência estão a aplicação mais freqüente de inseticidas, aumento da dose do produto, e substituição por um outro composto, geralmente mais caro e mais tóxico (Georghiou, 1983). Isto compromete os princípios do MIP em vista da maior contaminação ambiental, destruição dos inimigos naturais e elevação nos custos de controle da praga. Desta forma, o manejo da resistência de pragas

a produtos químicos se constitui num importante componente do MIP e vice-versa (Croft, 1990 e Georghiou, 1983).

A resistência de $S$. frugiperda já foi detectada para as principais classes de inseticidas em alguns países. Na Flórida, por exemplo, a intensidade da resistência tem variado de 2 a 216 vezes para piretróides, 12 a 271 vezes para fosforados e de 14 a 192 vezes para carbamatos (Yu, 1991). Em outro trabalho realizado por Yu (1992) na Flórida, detectou-se resistência desta praga ao piretróide fluvalinate (263 vezes), ao fosforado metil paration (516 vezes) e ao carbamato carbaril (560 vezes). No mesmo experimento, o autor verificou um aumento de 1,2 a 11 vezes na concentração de enzimas destoxificantes das populações de $S$. frugiperda provenientes do campo quando comparada com a de populações de laboratório.

\subsection{Resistência de pragas a inibidores da biossíntese de quitina}

A atividade inseticida dos análogos da benzoil-fenil uréias foi descoberta por volta de 1970 pela companhia Philips-Duphrar. As benzoil-fenil uréias, em geral, são formadas por dois anéis fenólicos substituídos e interligados por uma ponte de uréia (Retnakaran et al., 1985). Um dos primeiros análogos que mostrou ser efetivo no 
controle de insetos foi gerado a partir da combinação do herbicida dichlobenil com o herbicida à base de uréia, diuron (Retnakaran et al., 1985). A partir daí, vários análogos foram desenvolvidos e utilizados, como: diflubenzuron, penfluron, triflubenzuron e lufenuron.

Este grupo de inseticidas age inibindo a última etapa no processo da síntese de quitina, ou seja, na polimerização das unidades de $\mathrm{N}$-acetilglucosamino catalisadas pela enzima sintetase (Retnakaran et al., 1985). De acordo com Izawa et al. (1985), os inibidores da biossíntese de quitina interferem na polimerização de UDP-N-acetil-Dglucosamino, o último composto precursor da quitina durante sua síntese.

Os insetos intoxicados por produtos inibidores da biossíntese de quitina não conseguem sintetizar a quitina normalmente durante o processo de muda. Assim, não apresentam rigidez suficiente no corpo formado pela nova cutícula para se livrar da velha exúvia, ocorrendo o rompimento da parede do corpo durante o processo de muda, levando o inseto à morte. A intoxicação de insetos adultos pode atingir os ovos através da translocação do produto pelo ovário e impedir a síntese de quitina no embrião em formação (Izawa et al., 1985).

Os sintomas das benzoil-fenil uréias em lepidópteros podem ser separados em interrupção da ecdise, interrupção na alimentação e anomalias em adultos. A ecdise pode ser interrompida de quatro formas: a) completamente, levando o inseto à morte dentro de sua velha cutícula; b) parcialmente, a nova cutícula, que é muito frágil, pode romper-se e acarretar a morte do inseto; c) parcialmente com retenção apenas da cápsula cefálica, o inseto morre sem se alimentar; d) parcialmente com retenção apenas da cápsula cefálica no último instar, pode resultar em pupas mal formadas que não formarão adultos. A interrupção na alimentação pode ocorrer após uma metamorfose aparentemente normal, onde a mandíbula e o labro ficam dispostos de tal forma que o inseto não pode se alimentar. E por último, as anomalias em adultos, os quais podem apresentar severa inibição no vôo e na reprodução. Em alguns casos o adulto é formado, porém permanece moribundo e morre em seguida (Retnakaran et al., 1985). Em estudos realizados por Lyra et al. (1998) observou-se que lagartas de $3^{\circ}$ instar de Spodoptera littoralis (Boisd.) que receberam o lufenuron por meio de tratamento superficial de dieta artificial, deram 
origem a adultos que tiveram uma redução de 45 e $30 \%$ na fecundidade e no número de lagartas eclodidas respectivamente.

\subsubsection{Monitoramento da resistência}

A implementação de um programa de manejo da resistência é mais efetiva quando a frequiência de resistência ainda é baixa. No entanto, na maioria das vezes, a resistência só é diagnosticada quando há falhas no controle com o uso de um determinado produto (ffrench-Constant \& Roush, 1990).

O monitoramento é considerado essencial em programas de manejo de resistência de artrópodes a pesticidas (Dennehy \& Granett, 1984 e Staetz, 1985). Através do monitoramento é possível avaliar a eficiência de uma tática de manejo ou ainda determinar a situação atual de um produto em relação a uma praga para se iniciar o manejo.

A precisão requerida nos programas de monitoramento depende do seu propósito. Alguns programas são elaborados para detectar se as falhas no controle com pesticidas foram devido à resistência ou se foram devido à má aplicação do produto. (Dennehy \& Granett, 1984). Um programa de detecção e monitoramento preventivo da resistência, ou seja, antes que ocorram falhas no controle, requer uma metodologia mais eficiente pois o número de indivíduos resistentes ainda é baixo quando comparado ao caso da documentação de um problema já instalado (Curtis, 1985 e Tabashnik \& Croft, 1982).

Programas de monitoramento geralmente envolvem comparações de doses letais e coeficientes angulares das curvas de dose-resposta (Staetz, 1985 e Twine \& Reynolds, 1980). Esta metodologia se adequa a situações onde a resistência já atingiu altos níveis, mas pode ser ineficiente para detectá-la num programa preventivo onde a freqüência ainda é baixa (Roush \& Miller, 1986).

Nos casos onde a frequiência de resistência ainda é baixa, o método da concentração diagnóstica pode ser mais eficiente, desde que haja uma metodologia de 
bioensaio definida e adequada para a praga a ser testada (Roush \& Miller, 1986), levando em conta as características biológicas da praga e o modo de ação do produto.

Segundo Roush \& Miller (1986), a rapidez e a precisão na obtenção de resultados são as principais vantagens da técnica da concentração diagnóstica pois utiliza um número reduzido de indivíduos quando comparado com a técnica da comparação de doses letais.

Outro ponto crítico em estudos de resistência é o desenvolvimento de uma técnica adequada de bioensaio e a identificação do estágio ideal da praga para a realização dos bioensaios. A técnica de bioensaio deve ser o mais realista possível, de forma que simule o que ocorre no campo e seja simples o suficiente para viabilizar o estudo.

Segundo Retnakaran (1985), bioensaios realizados através de tratamento tópico ou tratamentos de efeito residual são apropriados para inseticidas de amplo espectro de ação como fosforados, carbamatos e piretróides, porém não são efetivos para inseticidas do grupo das benzoil-fenil uréias. Muitos trabalhos mostram que este grupo de produtos tem baixa toxicidade quando aplicados sobre a cutícula do inseto. Atualmente, os bioensaios de ingestão (tratamento superficial ou incorporação na dieta) são considerados como metodologia padrão para trabalhos com benzoil-fenil uréias.

Para a realização dos bioensaios com Plutella xylostella L., Ismail \& Wright (1991) e Furlong \& Wright (1994) visando estudos de resistência a reguladores de crescimento de insetos, utilizaram o bioensaio de ingestão. Para tanto, mergulharam círculos de folhas $(4,8 \mathrm{~cm}$ de diâmetro) por $10 \mathrm{~s}$ em solução inseticida. Após a imersão, os discos foram colocados para secar em papel filtro por $10 \mathrm{~s}$ e em seguida transferidos para papel alumínio corrugado por 1-2 $\mathrm{h}$ em temperatura ambiente. Os discos de folhas foram colocados em placas de Petri ( $5 \mathrm{~cm}$ de diâmetro) com o fundo coberto por papel de filtro umedecido e lagartas de $2^{\circ}$ instar foram inoculadas sobre os discos. No trabalho de Ismail \& Wright (1991) o bioensaio foi avaliado 17 dias após a infestação sendo que os discos de folhas eram substituídos por discos não tratados após 5 dias da infestação. No trabalho de Furlong \& Wright (1994) o bioensaio foi avaliado 5 dias após a infestação sem a substituição de discos de folhas. 
Em trabalhos com resistência de Cydia pomonella L. a diflubenzuron, deltametrina e fosalone desenvolvidos por Sauphanor \& Bouvier (1995) e Sauphanor et al. (1998) utilizourse o método de tratamento superficial de dieta artificial por meio de pulverização em torre. Recipientes plásticos de $2 \times 2 \times 2 \mathrm{~cm}$ contendo dieta artificial receberam o produto superficialmente. Após a pulverização, os recipientes permaneceram à temperatura ambiente por $2 \mathrm{~h}$ até a secagem do inseticida. Uma lagarta neonata foi inoculada por recipiente com o auxílio de um pincel. A mortalidade foi avaliada 5 dias após a infestação, considerando mortos os indivíduos que não se moviam ao serem tocados com um pincel.

Outra metodologia para a realização de bioensaios foi utilizada por Kotze \& Sales (2001) trabalhando com resistência de Lucilia cuprina (Wiedemann) a diflubenzuron. Grupos de 50 lagartas neonatas foram introduzidas em tubos contendo papel tratado com diflubenzuron diluído em acetona. A avaliação foi realizada 48 h após a infestação observando-se o número de indivíduos mortos e vivos.

Pode-se notar nos trabalhos envolvendo bioensaios com reguladores de crescimento que além da metodologia de bioensaio, o estágio da praga a ser testado deve ser muito bem definido pois as respostas de mortalidade podem ser completamente diferentes. Em pesquisa realizada por Granett \& Retnakaran (1977) verificou-se que lagartas de Choristoneura fumiferana (Clem.) tem um incremento na suscetibilidade ao diflubenzuron em instares mais avançados.

A suscetibilidade de Spodoptera littoralis (Boisd.) ao diflubenzuron foi maior

no $6^{\circ}$ instar quando comparado aos demais instares. O $1^{\circ}$ instar foi considerado o de menor suscetibilidade ao diflubenzuron (Salama \& Magd El-Din, 1977).

\subsubsection{Casos detectados de resistência}

Logo após o lançamento dos inseticidas reguladores de crescimento, o desenvolvimento da resistência a este grupo foi considerado impossível pelo fato destes produtos atuarem num processo vital para os insetos. Após alguns anos de utilização, falhas no controle de áreas tratadas com produtos deste grupo foram observadas. Foram 
realizados bioensaios para detecção da resistência e concluiu-se que o uso intensivo dos reguladores de crescimento havia selecionado populações resistentes no campo (Retnakaran et al., 1985).

Moffitt et al. (1988) detectaram resistência de C. pomonella a diflubenzuron. A razão de resistência encontrada foi de 2 vezes. Posteriormente, Sauphanor \& Bouvier (1995) detectaram uma razão de resistência de 370 vezes em C. pomonella a diflubenzuron.

Após a detecção de Moffit et al. (1988), outros autores também detectaram resistência a inseticidas do grupo dos reguladores de crescimento. Lin et al. (1989) detectaram resistência de $P$. xylostella a teflubenzuron. A razão de resistência encontrada foi de 31 vezes.

Kotze \& Sales (2001) estudaram a herança da resistência de L. cuprina a diflubenzuron. Os resultados mostraram que a resistência é poligênica com efeito maternal. Estudos anteriores conduzidos por Kotze (1993) indicaram que o aumento da atividade enzimática foi o mecanismo de resistência desenvolvido por L. cuprina a diflubenzuron. Resultados similares foram obtidos por Kotze \& Sales (2001), observando novamente o aumento enzimático na população resistente. Yu (1993) e Yu \& Nguyen (1994) também observaram um aumento enzimático em populações de $S$. frugiperda resistentes a diflubenzuron.

No caso da resistência de Musca domestica L. a diflubenzuron, foram detectados três mecanismos de resistência envolvidos: o aumento na atividade enzimática, a redução na penetração cuticular e uma maior rapidez na excreção do composto (Pimprikar \& Georghiou, 1979 e Pimprikar \& Georghiou, 1982). Em trabalhos conduzidos por Retnakaran et al. (1985) encontraram-se resultados semelhantes para $M$. domestica, o mecanismo de resistência a diflubenzuron foi uma combinação entre redução na penetração cuticular e um aumento no metabolismo. A linhagem resistente apresentou 50\% de redução na penetração quando comparada com a linhagem suscetível. O butóxido de piperonila aumentou a mortalidade da população resistente em 78 vezes e na linhagem suscetível a mortalidade não foi alterada, 
indicando que o aumento nas enzimas oxidativas era o principal mecanismo de resistência envolvido.

Laecke \& Degheele (1991) estudaram o mecanismo de resistência de Spodoptera exigua (Hübner) a diflubenzuron e teflubenzuron. Segundo os autores, a principal via de destoxificação destes inseticidas foi através da hidrólise e conjugação. $\mathrm{O}$ baixo sinergismo mostrado pelo butóxido de piperonila indica que as oxidases de função mista não representam o principal mecanismo de resistência da praga. Em outro trabalho, Laecke et al. (1995) salientaram que a resistência de S. exigua ao teflubenzuron pode ser devido a um eficiente processo de destoxificação através do aumento das enzimas da população resistente a inseticidas tradicionais.

Em estudos realizados por Guirguis et al. (1990) verificou-se que uma população de $S$. littoralis resistente a diflubenzuron apresentou baixa resistência cruzada com os inseticidas metomyl, profenofós e fenverelate $(2,33,2,63$ e 3,5 vezes respectivamente). Em trabalhos semelhantes, conduzidos por Laecke \& Degheele (1991), observou-se que há baixa resistência cruzada entre o teflubenzuron e alguns produtos tradicionais (piretróides e fosforados) para S. exigua. Observou-se que a razão de resistência de uma população de S. exigua foi de 100 vezes para os inseticidas tradicionais e não passou de 5 vezes para o teflubenzuron.

Ao contrário dos trabalhos citados anteriormente, em estudos conduzidos por Sauphanor et al. (1998), observourse resistência cruzada entre deltametrina e diflubenzuron. Uma população de $C$. pomonella foi coletada de um pomar tratado por cinco anos com piretróides e selecionada em laboratório com deltametrina por 7 gerações. Como resultado dessa seleção a população apresentou uma razão de resistência de 96, 6 e 3 vezes para diflubenzuron, deltametrina e fosalone respectivamente. Em outro trabalho de Sauphanor \& Bouvier (1995) observoutse ainda resistência cruzada de $C$. pomonella entre diflubenzuron e outras duas benzoil-fenil uréias registradas na França para o controle desse lepidóptero, o teflubenzuron (7 vezes) e o triflumuron (102 vezes).

Em estudos de dinâmica da resistência conduzidos por Suenaga et al. (1992), observou-se que a freqüência de indivíduos de $P$. xylostella resistentes a teflubenzuron 
variou com as estações do ano no Japão, diminuindo na primavera e aumentando no outono.

Outros trabalhos realizados com reguladores de crescimento, especificamente com o inseticida lufenuron foram desenvolvidos por Wilson \& Cryan (1996) e Wilson \& Cain (1997) estudando populações de Drosophila melanogaster Meigen provenientes de duas áreas geograficamente distintas nos Estados Unidos. Os resultados mostraram que as populações de campo foram mais de 100 vezes resistentes ao lufenuron que as populações suscetíveis de laboratório. Levantou-se a hipótese de que a resistência foi resultado da pressão seletiva exercida em anos anteriores envolvendo um inseticida tradicional. $\mathrm{O}$ carbamato propoxur foi um sério candidato devido ao seu uso intensivo durante as últimas 3 décadas. Entretanto, não foi encontrada nenhuma relação entre os dois inseticidas.

No trabalho desenvolvido por Wilson (1997) observou-se que D. melanogaster resistente ao lufenuron não apresentou resistência cruzada com o cyromazine.

Pesquisa envolvendo resistência com lufenuron ainda é escassa no mundo por se tratar de uma molécula recentemente introduzida. 


\section{MATERIAL E MÉTODOS}

O trabalho foi desenvolvido no Laboratório de Resistência de Artrópodes a Pesticidas do Setor de Entomologia da Escola Superior de Agricultura "Luiz de Queiroz", Universidade de São Paulo, Piracicaba, SP, no período de março de 1999 a setembro de 2000.

\subsection{Coleta e criação de Spodoptera frugiperda}

As populações de Spodoptera frugiperda J. E.Smith foram coletadas na cultura do milho, no período de setembro de 1999 a abril de 2000, em 5 estados do Brasil: Goiás, Minas Gerais, São Paulo, Paraná e Rio Grande do Sul. Foram coletadas e identificadas 3 populações do estado de São Paulo (SP-1, SP-2 e SP-3), 3 do Paraná (PR-1, PR-2 e PR-3), 2 de Goiás (GO-1 e GO-2), 2 de Minas Gerais (MG-1 e MG-2) e 2 do Rio Grande do Sul (RS-1 e RS-2). A população proveniente do Rio Grande do Sul (RS-1) onde o inseticida lufenuron foi pouco utilizado foi tomada como população suscetível de referência.

Aproximadamente 300 lagartas foram coletadas por propriedade e estas foram acondicionadas em caixas de isopor juntamente com folhas de milho e remetidas ao laboratório.

As lagartas de $S$. frugiperda provenientes do campo foram separadas da planta e inoculadas individualmente em tubos de vidro $(2,5 \mathrm{~cm}$ de diâmetro por $8 \mathrm{~cm}$ de altura) contendo dieta artificial à base de feijão, germe de trigo e levedura de cerveja, adaptada de Kasten et al. (1978). 
As pupas foram retiradas dos tubos com o auxílio de uma espátula e em seguida foram colocadas em placas de Petri de $10 \mathrm{~cm}$ de diâmetro por $1,5 \mathrm{~cm}$ de altura contendo vermiculita, onde foram mantidas encobertas por um copo plástico transparente até a emergência do adulto.

As mariposas foram acondicionadas em tubos de PVC (cloreto de polivinila) de $10 \mathrm{~cm}$ de diâmetro por $20 \mathrm{~cm}$ de altura revestidos internamente com papel filtro preso com fita adesiva, contendo nas extremidades superior e inferior placas de Petri de $15 \mathrm{~cm}$ de diâmetro. Na placa inferior foram colocados papel de filtro circular e também um recipiente de vidro de $15 \mathrm{~mL}$ de capacidade com tampa plástica contendo solução de mel na concentração de $10 \%$. Um orifício de $0,5 \mathrm{~cm}$ de diâmetro foi aberto na tampa plástica onde foi inserido um rolo dental de modo que a solução subisse por capilaridade e alimentasse às mariposas. Foram introduzidos 15 casais de mariposas por gaiola e estas foram mantidas em condições controladas de temperatura $\left(25 \pm 2^{\circ} \mathrm{C}\right)$ e fotofase $(14 \mathrm{~h})$. Os substratos para as posturas e solução de mel foram trocados a cada dois dias.

As massas de ovos foram acondicionadas em placas de Petri de $10 \mathrm{~cm}$ de diâmetro por $1,5 \mathrm{~cm}$ de altura juntamente com um pedaço de algodão embebido em água para manter a umidade interna da placa. Estas placas receberam outras do mesmo tamanho e foram vedadas com fita adesiva. As placas contendo posturas devidamente identificadas foram mantidas em câmara de germinação regulada a temperatura de $20^{\circ} \mathrm{C}$ e fotofase de $14 \mathrm{~h}$ até a eclosão das lagartas. Após a eclosão, duas lagartas foram inoculadas por tubo contendo dieta, num total de 200 tubos por população. Esse procedimento foi adotado para todas as populações.

A criação foi mantida à temperatura de $25 \pm 2^{\circ} \mathrm{C}$, umidade relativa de $70 \pm 10 \%$ e fotofase de $14 \mathrm{~h}$. 


\subsection{Procedimentos de bioensaio}

\subsubsection{Da criação para bioensaios}

As lagartas para bioensaios foram criadas em potes plásticos transparentes (capacidade de $100 \mathrm{~mL}$ ) contendo dieta artificial. Para tanto, uma camada de aproximadamente $1 \mathrm{~cm}$ de dieta artificial foi colocada no fundo dos potes $\mathrm{e}$ aproximadamente 50 a 100 lagartas recém-eclodidas foram inoculadas por recipiente. Estes potes foram fechados com tampas transparentes e mantidos à temperatura de $25 \pm 1^{\circ} \mathrm{C}$ e fotofase de 14 horas até que as lagartas atingissem o instar desejado para os bioensaios.

\subsubsection{Da preparação do bioensaio}

Para a realização dos bioensaios foi utilizada a técnica de tratamento superficial de dieta artificial. A dieta foi preparada e mantida em banho-maria regulado à $50^{\circ} \mathrm{C}$ para que se mantivesse no estado líquido. Com auxílio de uma micropipeta, foram depositados 1,25 $\mathrm{mL}$ de dieta artificial em cada célula da placa plástica contendo 24 células $\left(\operatorname{COSTAR}^{\circledR}\right)$. As placas contendo dieta permaneceram em câmara de fluxo laminar na presença de luz ultra violeta até a geleificação da dieta. Diversas concentrações de lufenuron (Match CE - 50g de lufenuron / L p.c., Novartis Agro) foram preparadas em água destilada, adicionando-se também o surfactante Triton $^{\circledR}$ na concentração de $0,1 \%$.

Utilizando-se uma micropipeta, as células contendo dieta geleificada receberam $30 \mu \mathrm{L}$ da solução inseticida lufenuron na concentração a ser testada e as lagartas do tratamento testemunha receberam somente solução de surfactante (Figura 1). As placas contendo o inseticida permaneceram na câmara de fluxo laminar por pelo menos 120 min. Após a secagem do inseticida, lagartas foram inoculadas individualmente nas células. Para $\mathrm{o}$ fechamento das placas foram utilizadas transparências fixadas por filme plástico transparente. Foram realizadas 4 perfurações 
por célula com auxílio de um alfinete entomológico para permitir aeração e minimizar a condensação dentro da célula. As placas foram mantidas em câmara climatizada regulada à temperatura de $25 \pm 1^{\circ} \mathrm{C}$ e fotofase de $14 \mathrm{~h}$.

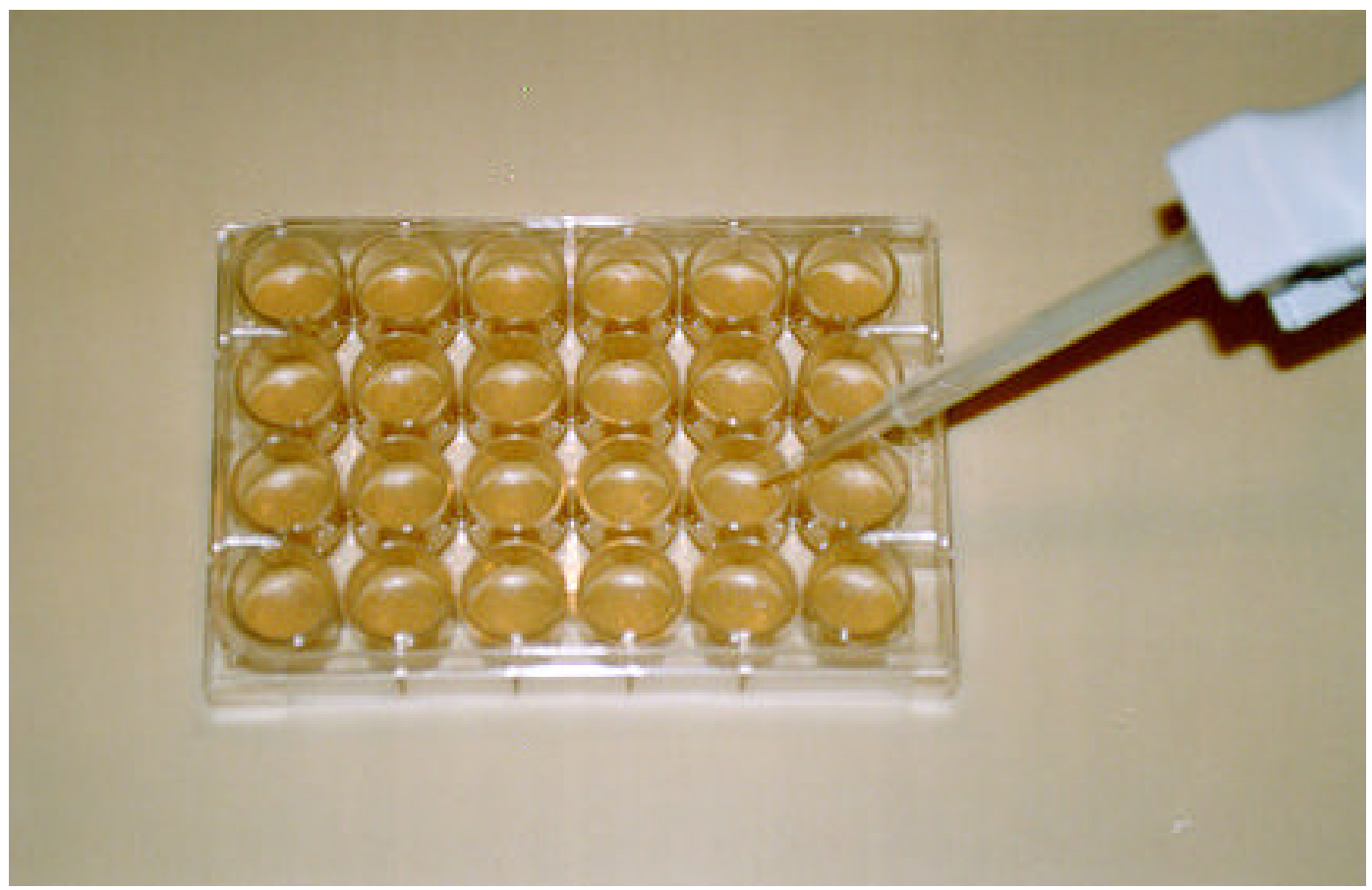

Figura 1 - Tratamento superficial de dieta artificial para realização de bioensaio 
A avaliação foi realizada considerando mortos os indivíduos que apresentaram pelo menos um terço do comprimento total do corpo com efeito do produto, ou seja, uma constrição dividindo o corpo em duas partes, uma onde a lagarta sofreu a ecdise e outra onde a mesma não conseguiu prosseguir a troca de pele.

Lagartas de $2^{\circ}$ e $3^{\circ}$ instares da população suscetível de referência (RS-1) foram testadas para a definição do instar em que a resposta seria mais adequada para a detecção da resistência. Simultaneamente ao estudo do instar mais adequado, foi avaliado também o melhor período para a avaliação do bioensaio. Para tanto, a mortalidade foi avaliada 48, 72, 96 e 120 horas após infestação das placas.

Os dados de mortalidade obtidos para cada instar $\left(2^{\circ}\right.$ e $\left.3^{\circ}\right)$ nos diferentes tempos de avaliação (48, 72, 96 e 120 h) foram submetidos à análise de Probit (Finney, 1971). Com auxílio do Programa Polo-PC (LeOra Software, 1987) o instar associado ao período de avaliação que apresentou a curva de concentração-resposta mais adequada ao modelo de Probit e também o maior coeficiente angular foi adotado como padrão para a realização dos demais estudos do presente projeto de pesquisa.

\subsection{Caracterização da suscetibilidade de Spodoptera frugiperda ao lufenuron}

Para a caracterização da linha básica de suscetibilidade foram testadas sete a oito concentrações de lufenuron, espaçadas logaritmicamente entre 0,18 e $10 \mu \mathrm{g}$ de lufenuron / $\mathrm{mL}$ de água, [ppm (I.A.)] de maneira que proporcionassem mortalidade entre 5 e 95\%. Foram avaliadas 5 populações provenientes de RS (RS-1), PR (PR-1), SP (SP1), MG (MG-2) e GO (GO-2).

Essa caracterização foi realizada de acordo com procedimentos de bioensaio reportados no item 3.2.2, utilizando-se lagartas de $3^{\circ}$ instar. A avaliação da mortalidade foi realizada 96 h após a infestação. Os dados de mortalidade para cada população foram submetidos a análise de Probit através do programa Polo-PC (LeOra Software, 1987).

Baseado nas respostas de concentração-mortalidade da população RS-1, duas concentrações diagnósticas (3,2 e $10 \mathrm{ppm})$ foram escolhidas seguindo os critérios 
apresentados por Roush \& Miller (1986). Estas concentrações foram utilizadas no programa de monitoramento da suscetibilidade de S. frugiperda.

\subsection{Monitoramento da suscetibilidade de populações de Spodoptera frugiperda ao lufenuron}

A suscetibilidade de populações de $S$. frugiperda ao inseticida lufenuron foi avaliada em cinco estados produtores de milho do Brasil: Rio Grande do Sul, Paraná, São Paulo, Minas Gerais e Goiás. De cada região, duas ou três propriedades foram coletadas e criadas conforme descrito no item 3.1. O monitoramento da suscetibilidade foi realizado através da metodologia da concentração diagnóstica com lagartas de $3^{\circ}$ instar e 96 h de período de avaliação utilizando-se as concentrações de 3,2 e 10 ppm de lufenuron. Foram realizadas pelo menos 30 repetições (20 lagartas/repetição) para cada propriedade. Os resultados obtidos foram submetidos à análise de variância hierárquica, onde as propriedades foram agrupadas em suas respectivas regiões (SAS Institute, 1993). Foram testados o efeito da região, assim como o efeito de propriedade dentro da região. O nível de significância dos testes foi de $5 \%$. 


\section{RESULTADOS E DISCUSSÃO}

\subsection{Procedimentos de bioensaio}

$\mathrm{O}$ bioensaio de tratamento superficial de dieta artificial se mostrou adequado para avaliar a suscetibilidade de Spodoptera frugiperda J. E. Smith a lufenuron. Pelos resultados da análise de Probit apresentados na Tabela 1, para lagartas de $2^{\circ}$ instar verifica-se que o coeficiente angular da curva de concentração-mortalidade aumenta com o tempo de exposição, até atingir o ponto máximo com 96 horas. Entre os períodos de avaliação testados, 96 horas após a infestação das élulas proporcionou o maior coeficiente angular 2,893 ( \pm 0,244) (Figura 2). Um dos principais objetivos em programas de monitoramento da resistência é definir uma técnica de bioensaio que permita uma maior discriminação entre as linhagens suscetíveis e resistentes da praga (ffrench-Constant \& Roush, 1990; Dennehy et al., 1983), um alto coeficiente angular permite maximizar as diferenças entre indivíduos suscetíveis e resistentes, e portanto, o maior valor do coeficiente angular é um dos parâmetros para a escolha do melhor tempo de avaliação.

Observa-se também na Tabela 1 que o tempo de 96 horas após a exposição foi o que apresentou o menor intervalo de confiança nas estimativas de $\mathrm{CL}_{95}$, além do menor valor de $\chi^{2}$ (10,136 com 5 graus de liberdade) adequando-se mais precisamente ao modelo de Probit. 
Tabela 1. Respostas de lagartas de $2^{\circ}$ instar da população suscetível de referência de Spodoptera frugiperda a lufenuron em diferentes tempos de avaliação com bioensaio de tratamento superficial de dieta artificial.

\begin{tabular}{|c|c|c|c|c|c|c|}
\hline $\begin{array}{c}\text { Tempo de } \\
\text { avaliação } \\
\left(\mathrm{HAI}^{\mathrm{a}}\right)\end{array}$ & $n^{b}$ & $\begin{array}{c}\text { Coeficiente } \\
\text { angular } \\
( \pm \text { desvio padrão) }\end{array}$ & $\begin{array}{c}\mathrm{CL}_{50}\left(\mathrm{ppm}^{\mathrm{c}}\right) \\
\text { (I.C. } 95 \%)\end{array}$ & $\begin{array}{l}\mathrm{CL}_{95}\left(\mathrm{ppm}^{\mathrm{c}}\right) \\
\text { (I.C. } 95 \%)\end{array}$ & $\chi^{2}$ & g.1. ${ }^{\mathrm{d}}$ \\
\hline 24 & 1582 & $0,880 \pm 0,91$ & $\begin{array}{c}50,585 \\
(15,104-3229,156)\end{array}$ & $\begin{array}{c}3746,585 \\
(251,178-90780417,785)\end{array}$ & 23,899 & 5 \\
\hline 48 & 1582 & $0,844 \pm 0,078$ & $\begin{array}{c}28,282 \\
(8,509-4478,861)\end{array}$ & $\begin{array}{c}2517,850 \\
(145,864- \\
2592551429,768)\end{array}$ & 39,065 & 5 \\
\hline 72 & 1239 & $1,791 \pm 0,086$ & $\begin{array}{c}1,454 \\
(0,657-3,205)\end{array}$ & $\begin{array}{c}12,055 \\
(4,794-162,244)\end{array}$ & 93,419 & 5 \\
\hline 96 & 1239 & $2,893 \pm 0,244$ & $\begin{array}{c}0,703 \\
(0,537-0,864)\end{array}$ & $\begin{array}{c}2,603 \\
(1,926-4,354)\end{array}$ & 10,136 & 5 \\
\hline 120 & 1239 & $2,507 \pm 0,156$ & $\begin{array}{c}0,498 \\
(0,394-0,621)\end{array}$ & $\begin{array}{c}2,256 \\
(1,569-4,072)\end{array}$ & 14,259 & 5 \\
\hline
\end{tabular}




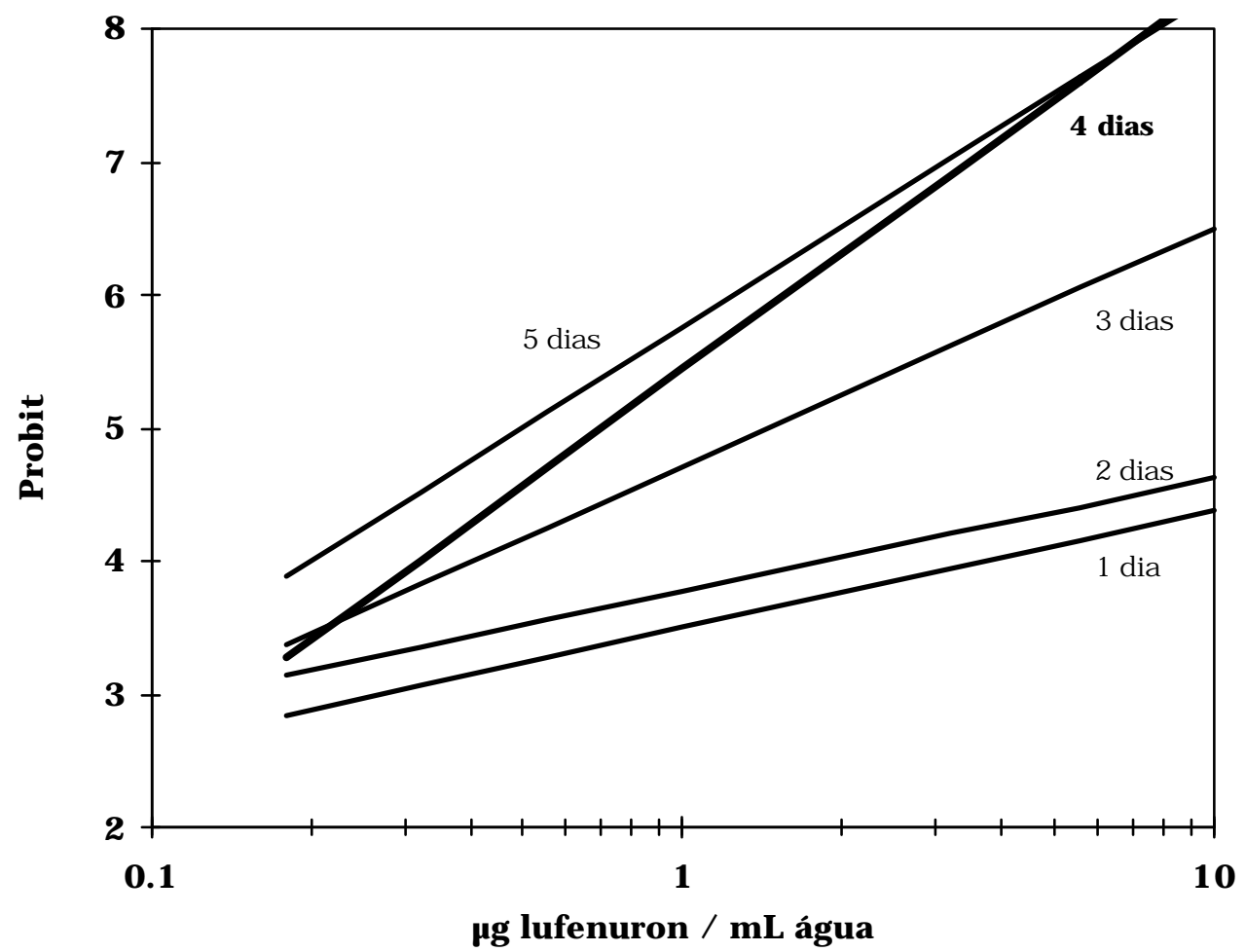

Figura 2 - Curvas de concentração-resposta de lagartas de $2^{\circ}$ instar da população suscetível de referência de Spodoptera frugiperda a lufenuron nos diferentes tempos de avaliação com bioensaio de tratamento superficial de dieta artificial. 
A mesma tendência dos resultados obtidos para lagartas de $2^{\circ}$ instar foi observada para lagartas de $3^{\circ}$ instar, ou seja, verificou-se um aumento no coeficiente angular com o tempo de avaliação (Tabela 2). Este aumento também atingiu o ponto máximo entre 72 e 120 horas após a exposição. Entre os períodos avaliados, 96 horas após a exposição apresentou o maior coeficiente angular para lagartas de $3^{\circ}$ instar.

Observa-se também na Tabela 2 que o período de 96 horas após a infestação foi o que apresentou o menor intervalo de confiança nas $\mathrm{CL}_{50}$ e $\mathrm{CL}_{95}$, além do menor valor de $\chi^{2}(20,459)$, adequando-se mais precisamente ao modelo de Probit.

Tabela 2. Respostas de lagartas de $3^{\circ}$ instar da população suscetível de referência de Spodoptera frugiperda a lufenuron em diferentes tempos de avaliação com bioensaio de tratamento superficial de dieta artificial.

\begin{tabular}{|c|c|c|c|c|c|c|}
\hline $\begin{array}{c}\text { Tempo de } \\
\text { avaliação } \\
\text { HAI }^{\mathrm{a}}\end{array}$ & $n^{b}$ & $\begin{array}{l}\text { Coeficiente angular } \\
( \pm \text { desvio padrão })\end{array}$ & $\begin{array}{l}\mathrm{CL}_{50}\left(\mathrm{ppm}^{\mathrm{c}}\right) \\
\text { (I.C. } 95 \%)\end{array}$ & $\begin{array}{l}\mathrm{CL}_{95}\left(\mathrm{ppm}^{\mathrm{c}}\right) \\
\text { (I.C. } 95 \%)\end{array}$ & $\chi^{2}$ & g.l. ${ }^{\mathrm{d}}$ \\
\hline 24 & 3211 & $1,285 \pm 0,149$ & $\begin{array}{c}51,479 \\
(21,268-910,618)\end{array}$ & $\begin{array}{c}981,121 \\
(148,072-610138,112)\end{array}$ & 22,634 & 6 \\
\hline 48 & 3209 & $2,208 \pm 0,089$ & $\begin{array}{c}3,615 \\
(2,208-6,321)\end{array}$ & $\begin{array}{c}20,095 \\
(9,770-163,754)\end{array}$ & 169,14 & 6 \\
\hline 72 & 3209 & $2,794 \pm 0,104$ & $\begin{array}{c}2,176 \\
(1,218-3,411)\end{array}$ & $\begin{array}{c}8,439 \\
(4,892-37,430)\end{array}$ & 203,39 & 6 \\
\hline 96 & 3209 & $3,740 \pm 0,192$ & $\begin{array}{c}1,089 \\
(0,930-1,238)\end{array}$ & $\begin{array}{c}2,999 \\
(2,501-3,918)\end{array}$ & 20,459 & 6 \\
\hline 120 & 3209 & $2,875 \pm 0,117$ & $\begin{array}{c}0,765 \\
(0,547-0,992)\end{array}$ & $\begin{array}{c}2,856 \\
(2,022-5,243)\end{array}$ & 68,609 & 6 \\
\hline \multicolumn{7}{|c|}{$\overline{\mathrm{a}}$ Horas após infestação } \\
\hline \multicolumn{7}{|c|}{ búmero de indivíduos testados } \\
\hline \multicolumn{7}{|c|}{ c $\mu \mathrm{g}$ lufenuron / mL água } \\
\hline raus de liberd & & & & & & \\
\hline
\end{tabular}




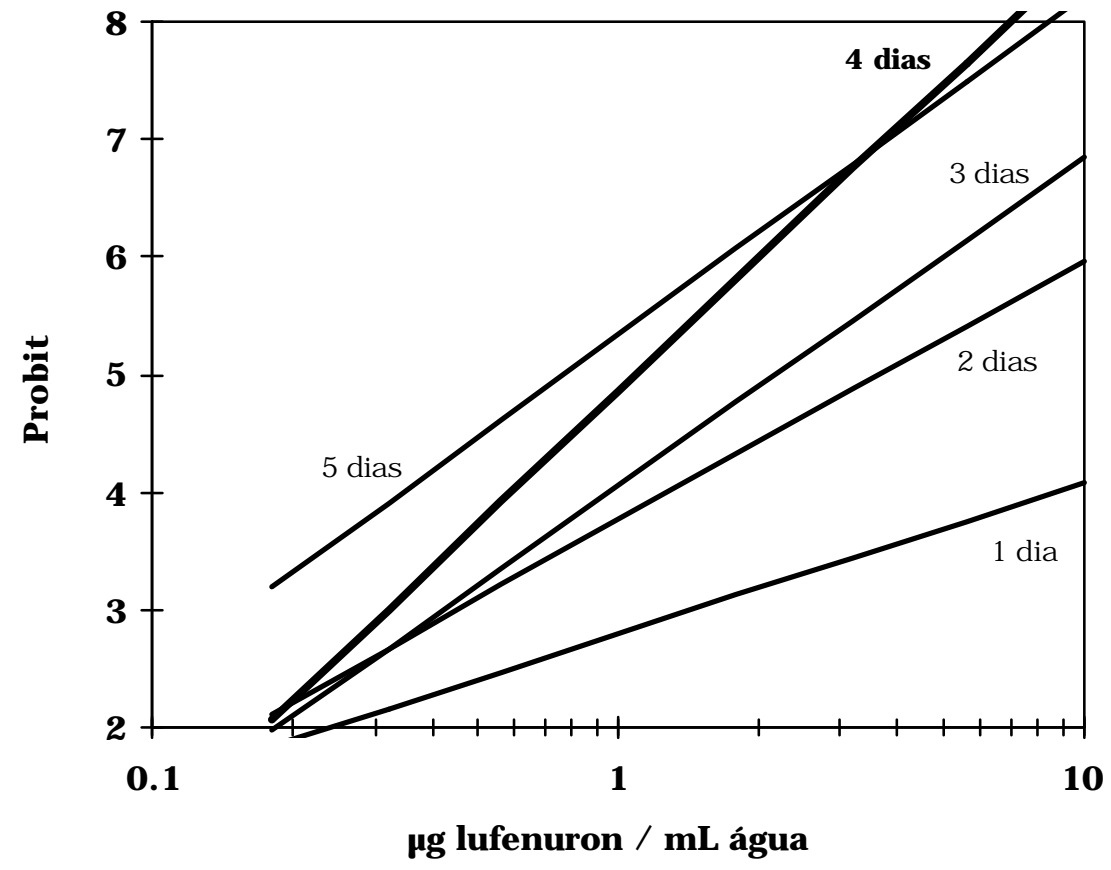

Figura 3 - Curvas de concentração-resposta de lagartas de $3^{\circ}$ instar da população suscetível de referência de Spodoptera frugiperda a lufenuron nos diferentes tempos de avaliação com bioensaio de tratamento superficial de dieta artificial. 
Os resultados dos bioensaios com lagartas de $2^{\circ}$ e $3^{\circ}$ instares de $S$. frugiperda mostraram que 96 horas após a exposição das lagartas ao lufenuron foi o melhor tempo de avaliação para ambos os instares (Tabelas 1 e 2).

Há estudos onde foram observadas diferenças quanto à suscetibilidade de lagartas de diferentes instares a produtos reguladores do crescimento dos insetos. A variação na suscetibilidade é esperada pois os produtos deste grupo atuam no crescimento dos insetos desorganizando sua ecdise, então, insetos em diferentes instares, ou seja, com diferentes balanços de hormônios e também diferentes valores de massa corpórea, apresentarão respostas diferenciadas dependendo do estágio de contato com o produto. Pesquisa realizada por Granett \& Retnakaran (1977) mostrou que lagartas de Choristoneura fumiferana (Clem.) tem um incremento na suscetibilidade ao diflubenzuron em instares mais avançados. Resultados semelhantes foram obtidos por Salama \& Magd El-Din (1977) onde a suscetibilidade de S. littoralis ao diflubenzuron foi maior no $6^{\circ}$ instar quando comparado aos demais instares. Diante disso, realizou-se neste trabalho a comparação entre as curvas de concentração-resposta de lagartas do $2^{\circ} \mathrm{e}$ $3^{\circ}$ instares (Tabela 3 e Figura 4). A curva obtida com lagartas de $3^{\circ}$ instar apresentou um coeficiente angular maior $(3,74 \pm 0,192)$ que a curva de lagartas de $2^{\circ}$ instar, além do menor intervalo de confiança para as $\mathrm{CL}_{50}$ e $\mathrm{CL}_{95}$. Sendo assim, lagartas de $3^{\circ}$ instar avaliadas com 96 horas após a infestação foram tomadas como padrão para a realização dos bioensaios de tratamento superficial de dieta artificial com lufenuron. 
Tabela 3. Respostas de lagartas de $2^{\circ}$ e $3^{\circ}$ instar da população suscetível de referência de Spodoptera frugiperda a lufenuron 96 horas após infestação com bioensaio de tratamento superficial de dieta artificial.

\begin{tabular}{|c|c|c|c|c|c|c|}
\hline Instar & $\mathrm{n}^{\mathrm{a}}$ & $\begin{array}{c}\text { Coeficiente } \\
\text { angular } \\
( \pm \text { desvio padrão) }\end{array}$ & $\begin{array}{c}\mathrm{CL}_{50}\left(\mathrm{ppm}^{\mathrm{b}}\right) \\
(\text { I.C. } 95 \%)\end{array}$ & $\begin{array}{c}\mathrm{CL}_{95}\left(\mathrm{ppm}^{\mathrm{b}}\right) \\
(\text { I.C. } 95 \%)\end{array}$ & $\chi^{2}$ & g.l. ${ }^{\mathrm{c}}$ \\
\hline $2^{\circ}$ & 1239 & $2,893 \pm 0,244$ & $\begin{array}{c}0,703 \\
(0,537-0,864)\end{array}$ & $\begin{array}{c}2,603 \\
(1,926-4,354)\end{array}$ & 10,136 & 5 \\
\hline $3^{\circ}$ & 3209 & $3,740 \pm 0,192$ & $\begin{array}{c}1,089 \\
(0,930-1,238)\end{array}$ & $\begin{array}{c}2,999 \\
(2,501-3,918)\end{array}$ & 20,459 & 6 \\
\hline
\end{tabular}




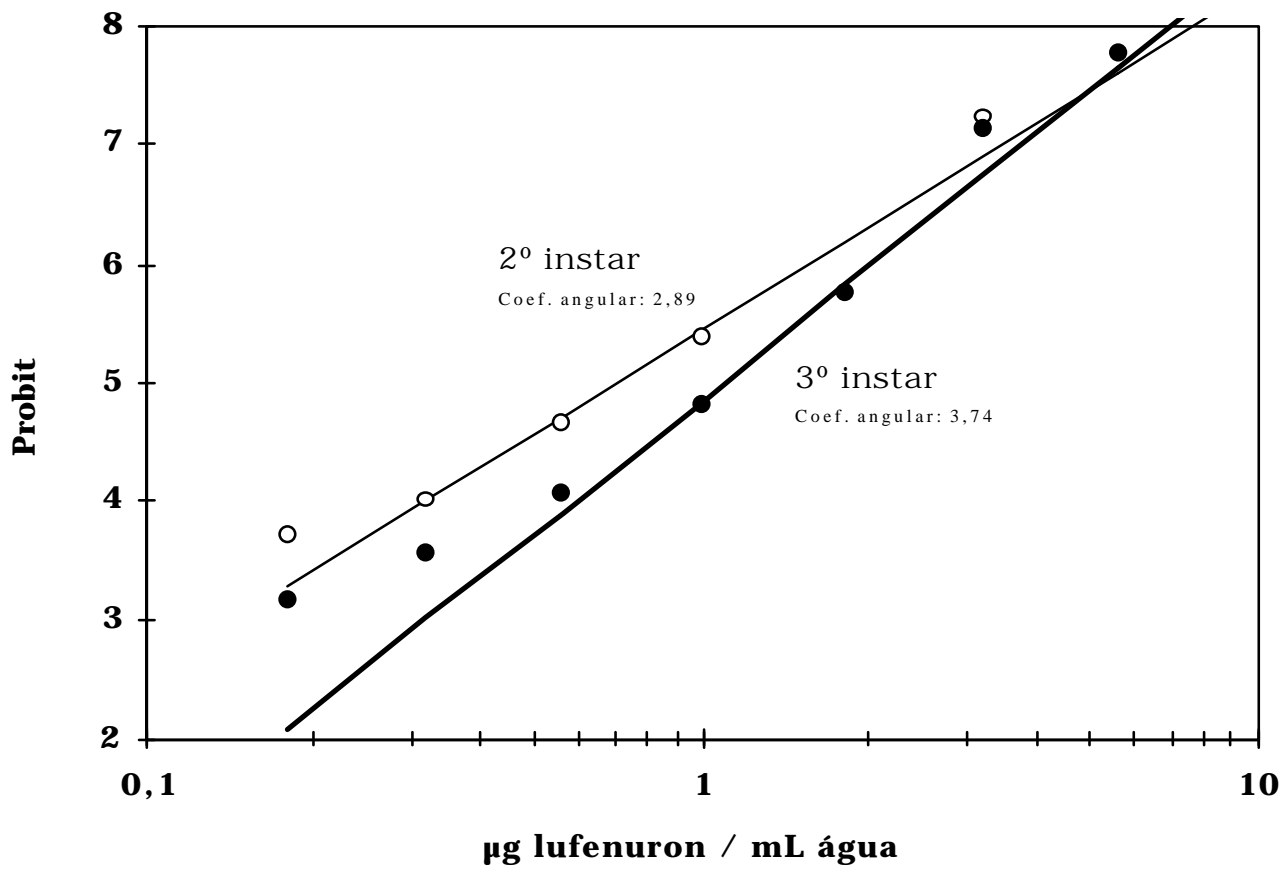

Figura 4 - Curvas de concentração-resposta de lagartas de $2^{\circ}$ e $3^{\circ}$ instares da população suscetível de referência de Spodoptera frugiperda a lufenuron 4 dias (96 h) após a infestação, com bioensaio de tratamento superficial de dieta artificial. 


\subsection{Caracterização da linha básica de suscetibilidade de Spodoptera frugiperda ao lufenuron}

Na Figura 5 observa-se a resposta da população suscetível de referência à diversas concentrações do lufenuron. Os resultados obtidos forneceram subsídios para a escolha de concentrações diagnósticas de acordo com os critérios apresentados por Roush \& Miller (1986) e ffrench-Constant \& Roush (1990). Segundo os autores, a concentração diagnóstica deve matar $99 \%$ da população suscetível, podendo ser utilizada uma concentração 2 ou 3 vezes maior que a $C_{99}$ desde que não elimine indivíduos resistentes. A CL99 estimada neste trabalho foi de 4,65 ppm através de um método padrão de bioensaio (ingestão superficial) e multiplicando-se este valor por um fator $(\approx$ 2), obteve-se um valor próximo a 10 ppm que foi adotado como concentração diagnóstica.

A fim de seguir a metodologia proposta por Roush \& Miller (1986) e também de não subestimar a estimativa de resistência de $S$. frugiperda a lufenuron, testou-se, além da concentração diagnóstica de 10 ppm, a concentração de 3,2 ppm (CL96) para fins de monitoramento de suscetibilidade de populações de $S$. frugiperda a lufenuron. 


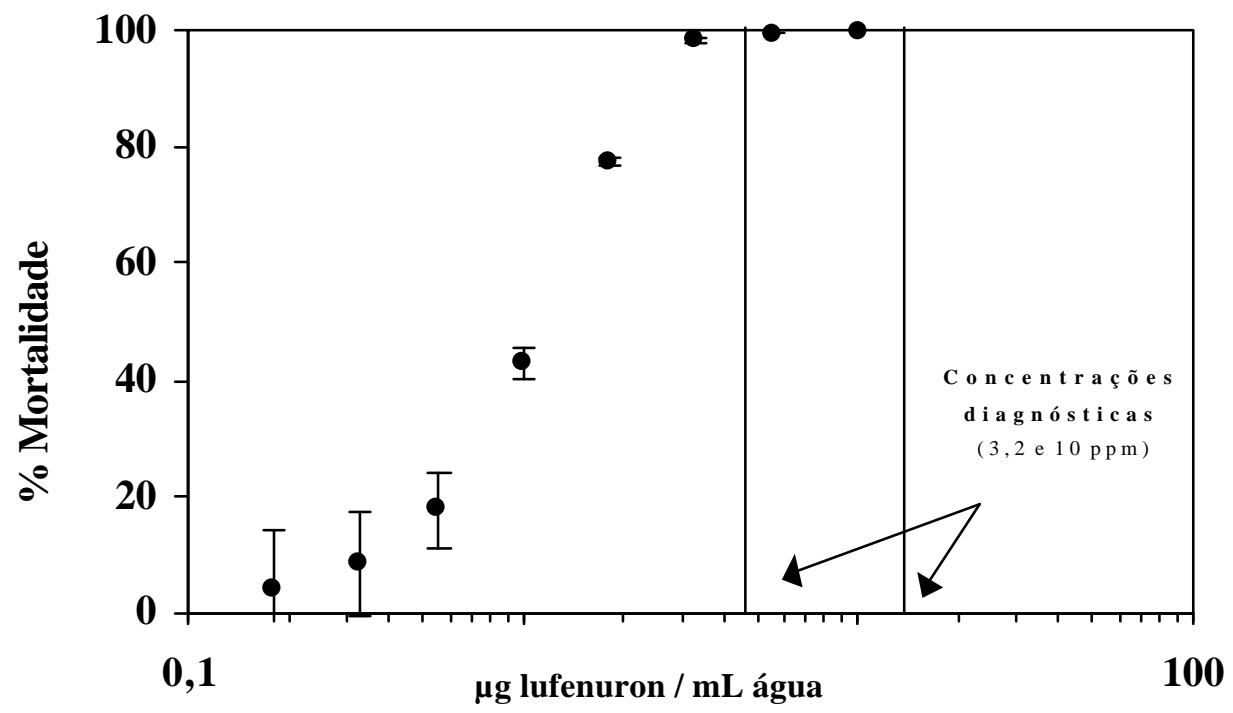

Figura 5 - Curva de concentração-resposta de lagartas de $3^{\circ}$ instar da população RS-1 (suscetível de referência) de Spodoptera frugiperda a lufenuron 4 dias (96 h) após a infestação, com bioensaio de tratamento superficial de dieta artificial. 


\subsection{Monitoramento da suscetibilidade de populações de Spodoptera frugiperda ao lufenuron}

Os resultados do monitoramento mostram que há diferenças estatísticas na suscetibilidade ao lufenuron em populações de $S$. frugiperda de diferentes regiões e também de populações dentro de cada região (Figuras 6 e 7). A região do Rio Grande do Sul (RS) diferiu estatisticamente de todas as outras $(\mathrm{P}<0,05)$, apresentando os menores valores de sobrevivência nas concentrações diagnósticas de 3,2 e 10. As demais regiões não apresentaram diferenças significativas entre si, com exceção da região de SP e GO que diferiram na concentração de 3,2 ppm. Essa diferença entre SP e GO se deve à contribuição da população SP-1 com maiores valores de sobrevivência (12\%) elevando a média de sua região, entretanto essas regiões não diferiram à concentração de 10 ppm.

A comparação entre as populações pela metodologia da $\mathrm{CL}_{50}$ representada na Tabela 6 e Figura 8 mostra que não houve diferenças estatísticas entre as populações testadas. Observa-se que a população RS-1 tem o maior valor de coeficiente angular $(3,74 \pm 0,192)$, portanto é a população mais homogênea quanto a suscetibilidade ao lufenuron. A homogeneidade de RS-1 era esperada porque trata-se de uma população proveniente do Rio Grande do Sul onde a pressão seletiva é menor que nas demais regiões por não haver o plantio de milho na safrinha e no inverno. As demais populações apresentaram coeficientes angulares mais baixos, com exceção da população de Minas Gerais onde o coeficiente foi mais próximo à população do RS. Os baixos valores dos coeficientes angulares das populações PR, SP e GO (entre 1,84 e 2,29) indicam uma maior heterogeneidade de populações (Tabela 6).

A ausência de diferenças estatísticas verificadas entre as populações pela técnica da comparação de $\mathrm{CL}_{50}$ era esperada pois a freqüência de resistência ao lufenuron no campo ainda é baixa por se tratar de uma molécula nova. Nestes casos, o método da concentração diagnóstica pode ser mais eficiente, desde que haja uma metodologia de bioensaio definida e adequada para a praga a ser testada (Roush \& Miller, 1986). 
Pode-se comprovar a ineficiência da comparação de $\mathrm{CL}_{50}$ quando os resultados obtidos pela técnica da dose diagnóstica foram analisados. Utilizando-se a concentração diagnóstica de 3,2 ppm de lufenuron observa-se que a população RS-1 (1,8\% de sobrevivência) diferiu estatisticamente das populações SP-1 (12\%), MG-1 (9,9\%) e MG$2(8,9 \%)$ (Tabela 4). As demais populações não diferiram estatisticamente. Utilizando-se a concentração diagnóstica de $10 \mathrm{ppm}$ novamente foram observadas diferenças estatísticas entre as populações. A população RS-1 com $0,3 \%$ de sobrevivência diferiu das populações SP-3 (6,9\%) e MG-1 (7,6\%) (Tabela 5). As demais populações não diferiram estatisticamente. Através da écnica da concentração diagnóstica detectou-se diferenças entre algumas populações ao passo que pela técnica de comparação de $\mathrm{DL}_{50}$ não houve diferenças estatísticas entre as populações, resultados estes que concordam com as observações feitas por Roush \& Miller (1986) e ffrench-Constant \& Roush (1990), quanto à sensibilidade das diferentes técnicas.

Analisando-se as Tabelas 4 e 5 observa-se também que todas populações estão num patamar de sobrevivência mais elevado que as populações do RS tanto à concentração de 3,2 ppm como à 10 ppm. Outra observação se refere à população SP -1, a qual apresentou o maior valor de sobrevivência à $3,2 \mathrm{ppm}(12 \%)$ o que poderia ser explicado pelo plantio seqüencial de milho típico na região (safra, safrinha e inverno) e assim as lagartas sofreram uma maior pressão seletiva.

As diferenças entre populações podem ser provenientes de uma variabilidade natural como também podem ser o início da seleção de indivíduos resistentes. Para que se possa afirmar que está havendo o desenvolvimento da resistência, é necessário submeter uma das populações com maior porcentagem de sobrevivência [Ex. SP-1 $(12 \%)]$ a sucessivas pressões seletivas com lufenuron, a fim de se obter uma população resistente homozigota. No presente estudo, foram realizadas várias tentativas de seleção de linhagens resistentes utilizando-se a CL95. A população foi facilmente selecionada e as lagartas criadas até a fase de pupa. Após a emergência dos adultos, os casais foram introduzidos em gaiolas conforme descrito no item 3.3. Diferentemente de adultos não submetidos ao lufenuron, estes indivíduos não realizaram postura, ou realizaram em 
número muito reduzido gerando ovos inférteis, impedindo a continuidade do processo de seleção.

Sabe-se que alguns inibidores da biossíntese de quitina podem afetar a reprodução de insetos. Lyra et al. (1998) estudaram os efeitos do tratamento com lufenuron na reprodução de $S$. littoralis. Lagartas de $3^{\circ}$ instar foram tratadas pelo método de bioensaio por ingestão. As lagartas sobreviventes foram criadas até a emergência do adulto. Análises sobre adultos mostraram que não houve diferenças no número de espermatóforos por fêmea, entretanto, a fecundidade e o número de lagartas eclodidas tiveram uma redução de 45 e 30\%, respectivamente. Retnakaran et al. (1985) observaram que adultos podem apresentar severa inibição no vôo e na reprodução, complementam ainda que em alguns casos o adulto é formado porém permanece moribundo e morre em seguida.

Os trabalhos envolvendo a esterilização de adultos, do ponto de vista da evolução da resistência, mostram que apesar do produto não oferecer controle satisfatório numa determinada área, os adultos gerados a partir das lagartas que sobreviveram ao produto podem não gerar descendentes e assim impedir a evolução da resistência. Entretanto, é preciso saber se os danos causados pelas lagartas remanescentes atingirão ou não o nível de dano econômico.

Outro ponto importante se refere aos variados cruzamentos que ocorrem no campo. Numa situação hipotética, como resultado de um cruzamento, é possível que uma fêmea produza descendentes resistentes sem os problemas de fecundidade. Estes questionamentos só poderão ser respondidos com a continuidade do trabalho e com o contínuo monitoramento da resistência. Vale ressaltar que tratam-se de hipóteses, as quais necessitam ser mais profundamente exploradas em trabalhos futuros. 
Tabela 4. Monitoramento da suscetibilidade de lagartas de $3^{\circ}$ instar de Spodoptera frugiperda a lufenuron através do bioensaio de tratamento superficial de dieta artificial com concentração diagnóstica de 3,2 $\mu$ g de lufenuron / $\mathrm{mL}$ de água.

\begin{tabular}{cccc}
\hline População & $\mathrm{n}$ & $\begin{array}{c}\text { \% média sobreviventes } \\
( \pm \text { desvio padrão })\end{array}$ & $(*)$ \\
\hline RS-1 & 720 & $1,80( \pm 0,50)$ & $\mathrm{a}$ \\
RS-2 & 432 & $3,60( \pm 0,90)$ & $\mathrm{a}$ \\
SP-1 & 408 & $12,00( \pm 1,30)$ & $\mathrm{b}$ \\
SP-2 & 576 & $5,70( \pm 1,60)$ & $\mathrm{ab}$ \\
SP-3 & 408 & $5,20( \pm 1,30)$ & $\mathrm{ab}$ \\
& & & $\mathrm{ab}$ \\
PR-1 & 432 & $6,30( \pm 1,90)$ & $\mathrm{ab}$ \\
PR-2 & 480 & $9,00( \pm 1,70)$ & $\mathrm{ab}$ \\
PR-3 & 432 & $9,00( \pm 2,60)$ & \\
GO-1 & 552 & $7,70( \pm 1,30)$ & $\mathrm{ab}$ \\
GO-2 & 456 & $8,10( \pm 1,50)$ & $\mathrm{ab}$ \\
MG-1 & 480 & $9,90( \pm 1,40)$ & $\mathrm{b}$ \\
MG-2 & 696 & $8,90( \pm 1,30)$ & $\mathrm{b}$ \\
\hline
\end{tabular}

(*) Médias seguidas de le tras diferentes diferem entre si pelo teste de Tukey ao nível de 5\%. 


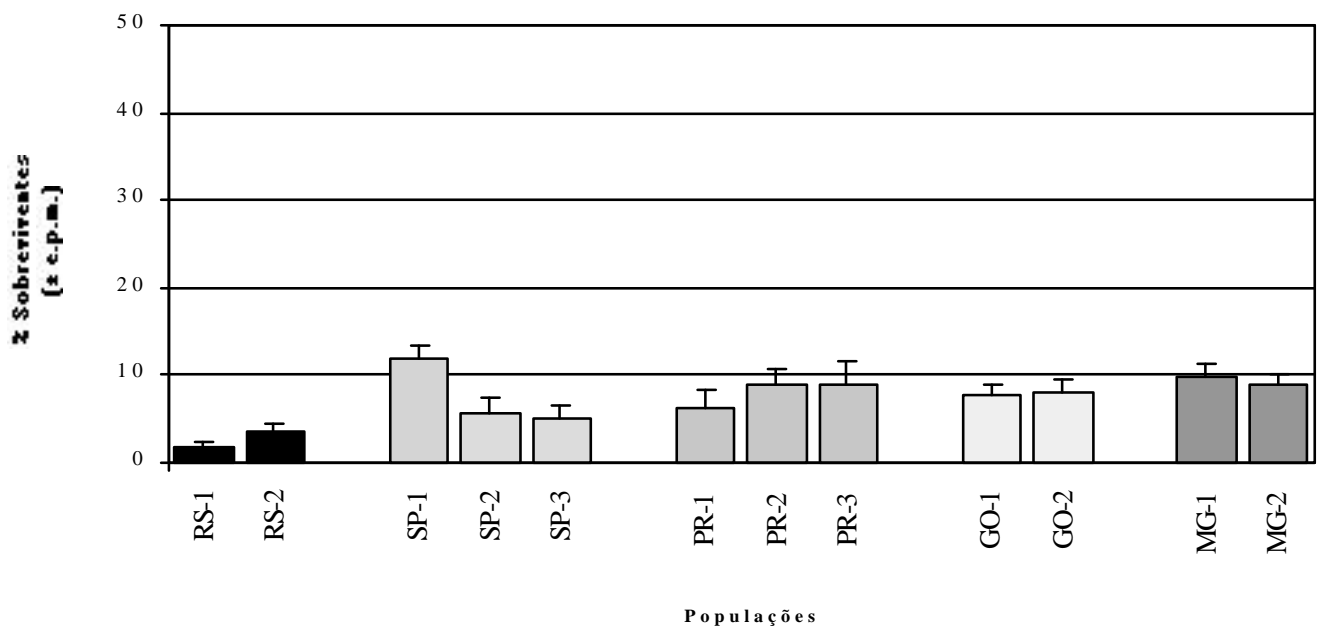

Figura 6 - Monitoramento da suscetibilidade de lagartas de $3^{\circ}$ instar de Spodoptera frugiperda a lufenuron através do bioensaio de tratamento superficial de dieta artificial com concentração diagnóstica de 3,2 $\mu \mathrm{g}$ de lufenuron / $\mathrm{mL}$ de água. 
Tabela 5. Monitoramento da suscetibilidade de lagartas de $3^{\circ}$ instar de Spodoptera frugiperda a lufenuron através do bioensaio de tratamento superficial de dieta artificial com concentração diagnóstica de $10 \mu \mathrm{g}$ de lufenuron / mL de água.

\begin{tabular}{cccc}
\hline População & $\mathrm{n}$ & $\begin{array}{c}\text { \% média sobreviventes } \\
( \pm \text { desvio padrão })\end{array}$ & $(*)$ \\
\hline RS-1 & 720 & $0,30( \pm 0,30)$ & $\mathrm{a}$ \\
RS-2 & 432 & $2,30( \pm 0,80)$ & $\mathrm{ab}$ \\
SP-1 & 432 & $5,60( \pm 2,00)$ & $\mathrm{ab}$ \\
SP-2 & 528 & $5,70( \pm 1,60)$ & $\mathrm{ab}$ \\
SP-3 & 432 & $6,90( \pm 1,40)$ & $\mathrm{b}$ \\
PR-1 & 408 & $4,70( \pm 1,40)$ & $\mathrm{ab}$ \\
PR-2 & 480 & $6,00( \pm 1,00)$ & $\mathrm{ab}$ \\
PR-3 & 480 & $2,90( \pm 1,20)$ & $\mathrm{ab}$ \\
GO-1 & 528 & $5,10( \pm 0,90)$ & $\mathrm{ab}$ \\
GO-2 & 432 & $5,60( \pm 0,90)$ & $\mathrm{ab}$ \\
MG-1 & 456 & $7,60( \pm 1,60)$ & $\mathrm{b}$ \\
MG-2 & 720 & $3,60( \pm 0,70)$ & $\mathrm{ab}$ \\
\hline
\end{tabular}

(*) Médias seguidas de le tras diferentes diferem entre si pelo teste de Tukey ao nível de 5\%. 


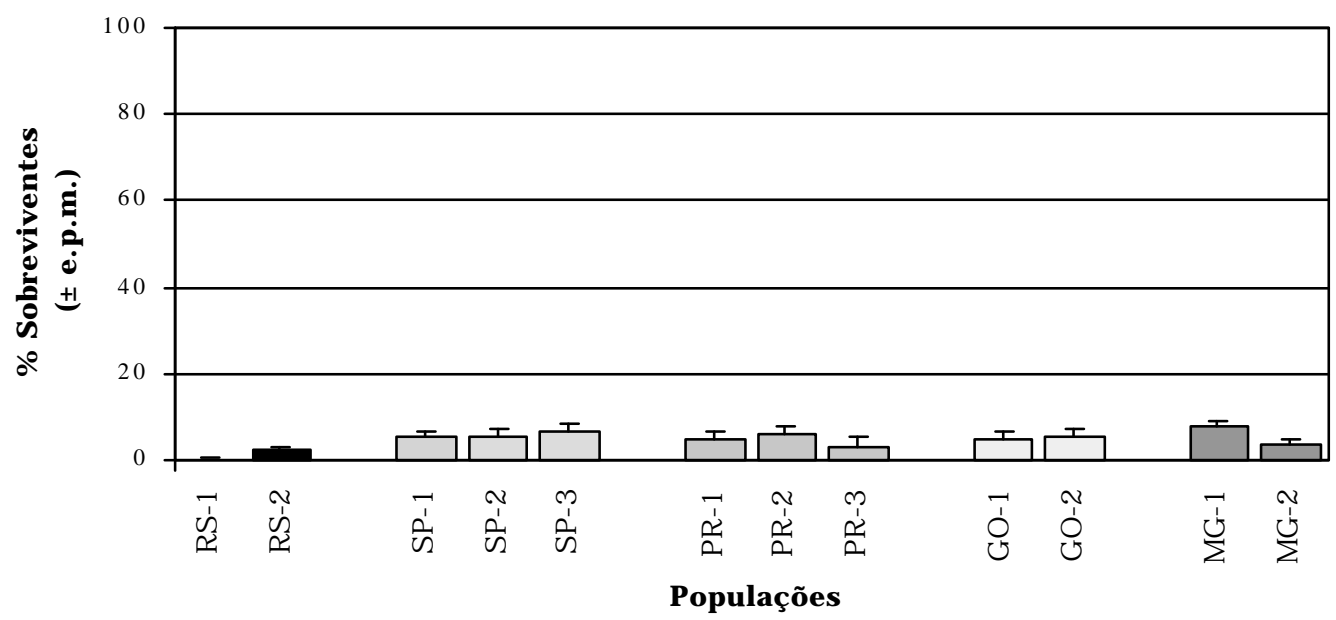

Figura 7 - Monitoramento da suscetibilidade de lagartas de $3^{\circ}$ instar de Spodoptera frugiperda a lufenuron através do bioensaio de tratamento superficial de dieta artificial com concentração diagnóstica de $10 \mu \mathrm{g}$ de lufenuron / mL de água. 
Tabela 6. Respostas de lagartas de $3^{\circ}$ instar de populações de Spodoptera frugiperda de 5 estados brasileiros ao lufenuron através do bioensaio de tratamento superficial de dieta artificial .

\begin{tabular}{|c|c|c|c|c|c|c|}
\hline Populações & $n^{\mathrm{b}}$ & $\begin{array}{c}\text { Coeficiente } \\
\text { angular } \\
( \pm \text { desvio padrão) }\end{array}$ & $\begin{array}{c}\mathrm{CL}_{50} \\
\text { (I.C. } 95 \%)\end{array}$ & $\begin{array}{c}\mathrm{CL}_{95} \\
\text { (I.C. 95\%) }\end{array}$ & $\chi^{2}$ & g.l. ${ }^{\mathrm{c}}$ \\
\hline $\mathrm{RS}^{\mathrm{a}}$ & 3209 & $3,740 \pm 0,192$ & $\begin{array}{c}1,089 \\
(0,930-1,238)\end{array}$ & $\begin{array}{c}2,999 \\
(2,501-3,918)\end{array}$ & 20,459 & 6 \\
\hline PR & 2040 & $2,181 \pm 0,86$ & $\begin{array}{c}1,059 \\
(0,553-1,640)\end{array}$ & $\begin{array}{c}6,010 \\
(3,522-17,891)\end{array}$ & 88,161 & 5 \\
\hline SP & 1992 & $1,840 \pm 0,801$ & $\begin{array}{c}1,152 \\
(0,543-1,834)\end{array}$ & $\begin{array}{c}9,019 \\
(4,909-35,126)\end{array}$ & 80,329 & 5 \\
\hline MG & 2718 & $3,603 \pm 0,911$ & $\begin{array}{c}1,322 \\
(0,844-1,827)\end{array}$ & $\begin{array}{c}5,662 \\
(3,830-11,209)\end{array}$ & 77,428 & 5 \\
\hline GO & 1076 & $2,29 \pm 0,168$ & $\begin{array}{c}1,390 \\
(0,379-2,209)\end{array}$ & $\begin{array}{c}7,262 \\
(4,602-25,490)\end{array}$ & 31,812 & 4 \\
\hline
\end{tabular}




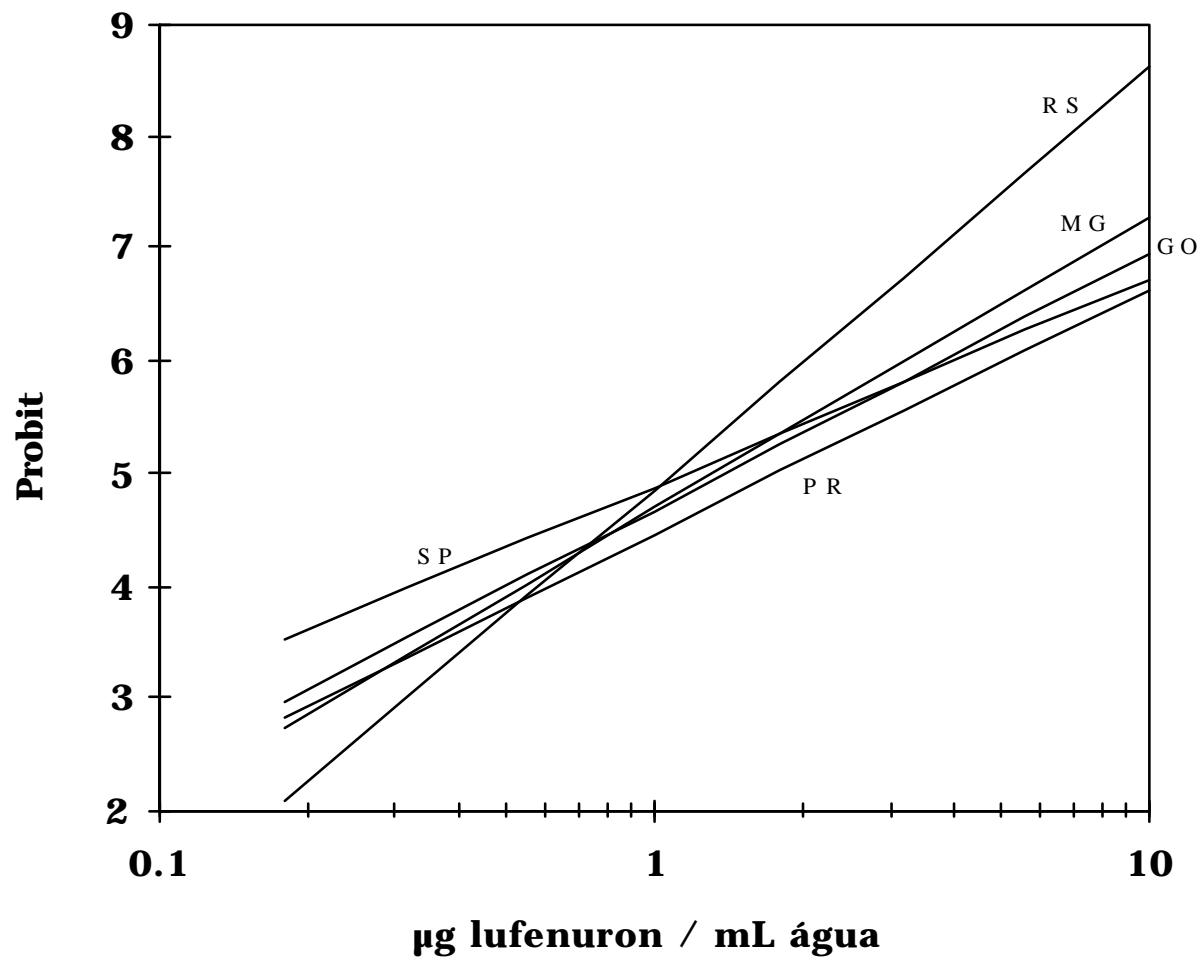

Figura 8-Curvas de concentração versus resposta de populações de Spodoptera frugiperda provenientes dos Estados do RS, PR, SP, MG e GO. Bioensaio de tratamento superficial de dieta artificial com lagartas de $3^{\circ}$ instar expostas por $96 \mathrm{~h}$ ao lufenuron. 
As diferenças quanto à suscetibilidade de populações de $S$. frugiperda observadas neste trabalho (Tabelas 4 e 5) podem ser o reflexo de diferenças no vigor e capacidade de desenvolvimento, atributos que são influenciados pelo genótipo e pelo estado nutricional do ovo que gerou o indivíduo. Marçon et al. (1999) também detectaram diferenças na suscetibilidade de populações de Ostrinia nubilalis (Hübner) a toxinas de Bacillus thuringiensis consideradas como diferenças no vigor entre populações.

A obtenção da linha básica de suscetibilidade de $S$. frugiperda antes da ocorrência de falhas no campo representa o primeiro passo de um programa preventivo de manejo da resistência. Portanto, os dados mostram que há diferenças na suscetibilidade entre as regiões no Brasil e servem como ponto de partida em futuros trabalhos de monitoramento da resistência.

A partir dos dados gerados neste estudo pode-se dar prosseguimento à linha de pesquisa avaliando-se a evolução da resistência nas principais regiões produtoras de milho do Brasil ou ainda selecionando-se indivíduos resistentes para estudos voltados à análise da herança da resistência, mecanismos de resistência e resistência com outros produtos.

Os estudos envolvendo resistência de insetos a inseticidas somente têm importância se os princípios do manejo ecológico de pragas forem seguidos. Especificamente no caso das benzoil-fenil uréias, é mandatório a observação do horário de alimentação da praga para aplicação do produto, do período de suscetibilidade que ocorre durante a fase larval da praga e da velocidade de ação mais lenta típica destes produtos, pois o estágio de desenvolvimento que a lagarta se encontra no momento da aplicação é fundamental para o sucesso no controle. 


\section{CONCLUSÕES}

O bioensaio de tratamento superficial de dieta artificial com lufenuron é adequado para avaliar a suscetibilidade de populações de Spodoptera frugiperda J. E. Smith a este inseticida.

A utilização de lagartas de $3^{\circ}$ instar de $S$. frugiperda expostas por um período de 4 dias ( 96 h) é adequada para o bioensaio de tratamento superficial de dieta artificial com lufenuron.

Há diferenças na suscetibilidade a lufenuron em populações de $S$. frugiperda coletadas em diferentes regiões do Brasil. 


\section{REFERÊNCIAS BIBLIOGRÁFICAS}

CARVALHO, R.P.L. Danos, flutuação da população, controle e comportamento de Spodoptera frugiperda (J.E. Smith, 1797) e suscetibilidade de diferentes genótipos de milho, em condições de campo. Piracicaba, 1970. 170p. Tese (Doutorado) - Escola Superior de Agricultura " Luiz de Queiroz", Universidade de São Paulo.

CROFT, B. A. Developing a philosophy and program of pesticide resistance management. In: ROUSH, R.T.; \& TABASHNIK, B.E. (Ed.) Pesticide resistance in arthropods. New York: Chapman and Hall, 1990. cap.11, p. 277-296

CRUZ, I. Manejo Integrado de pragas de milho com ênfase para o controle biológico. In: 4 CIClO DE PALESTRAS SOBRE CONTROLE BIOLÓGICO DE PRAGAS, 4, Campinas, 1995. Anais. Campinas: Instituto Biológico, 1995. p.48-92.

CURTIS, C.F. Theoretical models of the use of insecticide mixtures for the management of resistance. Bulletin of Entomology, v.75, p.259-265, 1985.

DENNEHY, T.J.; GRANETT, J. Monitoring dicofol resistant spider mites (Acari: Tetranychidae) in California cotton. Journal of Economic Entomology, v.77, p.1386-1392, 1984.

DENNEHY, T.J.; GRANETT, J.; LEIGH, T.F. Relevance of slide-dip and residual bioassay comparisions to detection of resistance in spider mites. Journal of Economic Entomology, v.76, p.1225-1230, 1983. 
ESTEVES, A.; PEREIRA, E.B.C.; RUSCHEL, R. Avaliação de características agronômicas de cultivares de milho (Zea mays) introduzidas, no plantio da safrinha. In: CONGRESSO NACIONAL DE MILHO E SORGO, 20., Goiânia, 1994. CentroOeste: cinturão de milho e sorgo no Brasil; resumos. Goiânia: ABMS; EMGOPA; EMBRAPA, CNPMS; UFG; EMATER-GO, 1994. p.36.

ESTRADA, F.A.R. Lista preliminar de insetos asociados al maíz en Nicaragua. Turrialba, v.10, n.2, p.68-73, 1960.

FFRENCH-CONSTANT, R.H.; ROUSH, R. T. Resistance detection and documentation: the relative roles of pesticidal and biochemical assays. In ROUSH, R.T.; TABASHNIK, B.E. (Ed.) Pesticide resistance in arthropods. New York: Chapman and Hall, 1990. cap. 2, p.4-38.

FINNEY, D.J. Probit analysis. 3. ed. London, Cambridge University, 1971. 333p

FNP CONSUlTORIA E COMÉRCIO. Agrianual 2001: Anuário da agricultura brasileira. São Paulo, 2000. p.417-438.

FURLONG, M.J.; WRIGHT, D.J. Examination of stability of resistance and crossresistance patterns to acylurea insect growth regulators in field populations of the diamondback moth, Plutella xylostella, from Malasya. Pesticide Science, v.42, p.315-326, 1994.

GARCIA, J.C. Situação da cultura do milho no Brasil. In: EMPRESA BRASILEIRA DE PESQUISA AGROPECUÁRIA. Centro Nacional de Pesquisa de Milho e Sorgo.

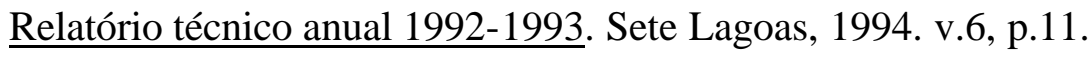


GEORGHIOU, G.P. Management of resistance in arthropods,. In: GEORGHIOU, G.P.; SAITO, T. (Ed). Pest resistance to pesticides. New York: Plenum, 1983. cap. p. 769-792.

GEORGHIOU, G.P.; TAYLOR, C.E Genetic and biological influences in the evolution of insecticide resistance. Journal of Economic Entomology, v.70, n.3, p.319-323, 1977a.

GEORGHIOU, G.P.; TAYLOR, C.E. Operational influences in the evolution of insecticide resistance. Journal of Economic Entomology, v.70, p.653-658, 1977b.

GEORGHIOU, G. P.; TAYLOR, C. E. Factors influencing the evolution of resistance. In: NATIONAL ACADEMY OF SCIENCES. (ed.), Pesticide resistance: strategies and tactics for management. Washington, 1986. cap.3, p.157-169.

GRANETT, J.; RETNAKARAN, A. Stadial susceptibility of Eastern spruce budworm, Choristoneura fumiferana (Lepidoptera: tortricidae), to the insect growth regulator Dimilin. Canadian Entomologist, v.109, p.893-894, 1977.

GUIRGUIS, M. W.; WATSON, W. M.; EL-HAMAKY, A. M. Changes in susceptibility to insecticides of selected strains of Spodoptera littoralis (Bosid) subjected to selection pressure with diflubenzuron for one generation (Egypt). Journal of Agricultural Research, v.14, n.3, p.1391-1402, 1990.

ISMAIL, F.; WRIGHT, J.W. Cross-resistance between acylurea insect growth regulators in a strain of Plutella xylostella L. (Lepidoptera: Yponomeutidae) from Malaysia. Pesticide Science, v.33, p.359-370, 1991. 
IZAWA, Y.; UCHIDA, M.; SUGIMOTO, T. ASAI, T. Inhibition of chitin biosynthesis by buprofezin analogs in relation to their activity controlling Nilaparvata lugens Stal. Pesticide Biochemistry and Physiology, v.24, p.343-347, 1985.

KASTEN Jr., P.; PRECETTI, A.A.C.M.; PARRA, J.R.P. Dados biológicos comparativos de Spodoptera frugiperda (J.E. Smith, 1797) em duas dietas artificiais e substrato natural. Revista da Agricultura, v.53, n.1/2, p.68-78, 1978.

KOTZE, A.C. Cytochrome, P450 monooxygenases in larvae of insecticide-susceptible and -resistant strains of the Australian sheep blowfly, Lucilia cuprina. Pesticide Biochemistry and Physiology, v.46, p.65-72, 1993.

KOTZE, A.C.; SALES, N. Inheritance of diflubenzuron resistance and monooxygenase activities in laboratory-selected strain of Lucilia cuprina (Diptera: Calliphoridae). Journal of Economic Entomology, v.94, n.5, p.1243-1248, 2001.

LAECKE, K. V.; DEGHEELE, D. Detoxification of diflubenzuron and teflubenzuron in the larvae of the beet armyworm (Spodoptera exigua) (Lepidoptera: Noctuidae). Pesticide Biochemistry and Physiology, v.40, n.2, p.181-190, 1991.

LAECKE, K. V.; SMAGGHE, G.; DEGHEELE, D. Detoxifying enzymes in greenhouse and laboratory strain of beet armyworm (Lepidoptera: Noctuidae). Journal of Economic Entomology, v.88, n.4, p.777-781, 1995.

LEORA SOFTWARE. POLO-PC: a user's guide to Probit $O$ r LOgit analysis. Berkeley, 1987. 20p. 
LIN, J.G; HUNG, C. F.; SUN, C. N. Teflubenzuron resistance and microsomal monooxygenases in larvae of diamondback moth. Pesticide Biochemistry and Physiology, v. 35, n.1, p. 20-25, 1989.

LYRA, J.R.M.; FERRAZ, J.M.G.; SILVA, A.P.P. Action of chitin synthesis inhibitors on reproduction of Spodoptera littoralis (Boisd.) (Lepidoptera: Noctuidae). Anais da Sociedade Entomológica do Brasil, v.27, n.4, p.569-576, 1998.

MARÇON, P.C.R.G.; YOUNG, L.J.; STEFFEY, K.L.; SIEGFRIED, B.D. Baseline susceptibility of European corn borer (Lepidoptera: Crambidae) to Bacillus thuringiensis toxins. Journal of Economic Entomology, v.92, n.2, p.279-285, 1999.

METCALF, R.L. Changing role of insecticides in crop protection. Annual Review of Entomology, v.25, p.219-56, 1980.

MOFFITT, H. R.; WESTIGARD, P.H.; MANTEY, K. D.; BAAN, H. E VAN DE. Resistance to diflubenzuron in the codling moth (Lepidoptera: Tortricidae). Journal of Economic Entomology, v.81, n.6, p.1511-1515, 1988.

NALIN, D.M. Biologia, nutrição quantitativa e controle de qualidade de populações de Spodoptera frugiperda (J.E. Smith, 1797) (Lepidoptera: Noctuidae) em duas dietas artificiais. Piracicaba, 1991. 150p. Tese (Doutorado) - Escola Superior de Agricultura “Luiz de Queiroz", Universidade de São Paulo.

PASHLEY, D.P.; MARTIN, J.A. Reproductive incompatibility between host strains of the fall armyworm (Lepidoptera: Noctuidae). Annals of the Entomological Society of America, v.80, n.6, p.731-733, 1987. 
PASHLEY, D.P.; HAMMOND, A.M.; HARDY, T.M. Reproductive isolating mechanisms in fall armyworm host strains (Lepidoptera: Noctuidae). Annals of the Entomological Society of America, v.85, n.4, p.400-405, 1992.

PIMPRIKAR, G.D.; GEORGHIOU, G. Mechanisms of resistance to diflubenzuron in the house fly, Musca domestica (L.). Pesticide Biochemistry and Physiology, v.12, p.10-22, 1979.

PIMPRIKAR, G.D.; GEORGHIOU, G. Effect of sesamex on the in vivo metabolism of diflubenzuron in larvae of susceptible and resistance strains of the housefly, Musca domestica L. Journal of Agricultural and Food Chemistry, v.30, p.615-618, 1982.

RETNAKARAN, A.; GRANETT, G.; ENNIS, T. Insect growth regulators. In: KERKUT, G. A.; GILBERT, L. I. (Ed.) Comprehensive insect physiology, biochemistry and pharmacology. Oxford: Pergamon, 1985. cap. 12, p.529-601.

RIZZO, H.F.; LA ROSA, F.R. Aspectos morfologicos y biologicos de la "oruga militar tardia" (Spodoptera frugiperda) (Lep.: Noctuidae). Revista de la Faculdad de Agronomia, v.13, n.2-3, p.193-199, 1992.

ROUSH, R. T.; MILLER, G. L. Considetarions for design of insecticide resistance monitoring programs. Journal of Economic Entomology, v.79, p.293-298, 1986.

SAS INSTITUTE. SAS/STAT: users guide. Cary, 1993. 1022p.

SALAMA, H.S.; MAGD EL-DIN, M. Effect of the moulting inhibitor Dimilin on the cotton leafworm Spodoptera littoralis Boisd. In Egypt. Zoological Angewaudte Entomologist, v.83, p.415-419, 1977. 
SAUPHANOR, B.; BOUVIER, J.C. Cross-resistance between benzoylureas and benzoylhydrazines in the codling moth, Cydia pomonella L. Pesticide Science, v.45, n.4, p.369-375, 1995.

SAUPHANOR, B.; BOUVIER, J.C.; BROSSE, V. Spectrum of insecticide resistance in Cydia pomonella (Lepidoptera: Tortricidae) in Southeastern France. Journal of Economic Entomology, v.91, n.6, p.1225-1231, 1998.

STAETZ, C. A. Susceptibility of Heliothis virescens (F.) (Lepidoptera: Noctuidae) to permethrin from across the cotton belt: a five-year study. Journal of Economic Entomology, v.78, p.505-510, 1985.

SUENAGA, A.; TANAKA, A.; MURATA, M.; HORIKIRI, M. Development of chitin synthesis inhibitor resistance in the diamondback moth, Plutella xylostella (L.) (Lepidoptera: Yponomeutidae). Proceedings of the Association for Plant Protection of Kyushi, v.38, p.129-131, 1992.

TABASHNIK, B.E.; CROFT, B. Managing pesticide resistance in crop-arthropod complexes: interactions between biological and operational factors. Environmental Entomological, v.11, p.1137-1144, 1982.

TWINE, P. H.; REYNOLDS, H. T. Relative susceptibility and resistance of the tobacco budworm to methyl parathion and syntetic pyrethroids in Southern California. Journal of Economic Entomology, v.73, p.239-242, 1980.

VEENSTRA, K.H.; PASHLEY, D.P.; OTTEA, J.A. Host-plant adaptation in fall armyworm host strains: comparison of food consumption, utilization, and detoxification enzyme activities. Annals of the Entomological Society of America, v.88, n.1, p.80-91,1995. 
VIANA, P. A. Efeito de doses do inseticida clorpirifós para o controle da lagarta-docartucho, Spodoptera frugiperda (Lepidoptera: Noctuidae), na cultura do milho. In: EMPRESA BRASILEIRA DE PESQUISA AGROPECUÁRIA. Relatório técnico anual 1992-1993. Sete Lagoas, 1994. v.6,9, p.65.

WILSON, T. G. Cyromazine toxicity to Drosophila melanogaster (Diptera: Drosophilidae) and lack of cross-resistance in natural population strains. Journal of Economic Entomology, v.90, n.5, p. 1163-1169, 1997.

WILSON, T. G.; CRYAN, J. R High genetic variability in Drosophila melanogaster for susceptibility to lufenuron, and insecticide that inhibits chitin synthesis. Molecular Genetics and Evolution of Resistance, p.141-148, 1996.

WILSON, T. G.; CAIN, J. W. Resistance to the insecticides lufenuron and propoxur in natural populations of Drosophila melanogaster (Diptera: Drosophilidae). Journal of Economic Entomology, v 90, n.5, p.1131-1136, 1997.

YU, S.J. Age variation in insecticide susceptibility and detoxification capacity of fall armyworm (Lepidpotera: Noctuidae) larvae. Journal of Economic Entomology, v.76, n.2, p.219-222, 1983.

YU, S.J. Insecticide resistance in the fall armyworm, Spodoptera frugiperda (J. E. Smith). Pesticide Biochemistry and Physiology, v.39, p.84-91,1991

YU, S.J. Detection and Biochemical characterization of insecticide resistance in fall armyworm (Lepidoptera: Noctuidae). Journal of Economic Entomology, v.85, n.3, p.675-682, 1992 
YU, S.J. Inheritance of insecticide resistance and microsomal oxidases in the diamondback moth (Lepidoptera: Yponomeutidae). Journal of Economic Entomology, v.86, p.980-683, 1993.

YU, S.J.; NGUYEN, S.N. Inheritance of carbaryl resistance and microsomal oxidases in the fall armyworm (Lepidoptera: Noctuidae) Journal of Economic Entomology, v.87, n.2, p.301-304, 1994. 